\title{
Pattern Recognition of Amino Acid Signatures in Retinal Neurons
}

\author{
R. E. Marc, ${ }^{1}$ R. F. Murry, ${ }^{1}$ and S. F. Basinger ${ }^{2}$ \\ ${ }^{1}$ John Moran Eye Center, University of Utah Health Sciences Center, Salt Lake City, Utah 84132 and ${ }^{2}$ Cullen Eye \\ Institute, Baylor College of Medicine, Houston, Texas 77030
}

\begin{abstract}
Pattern recognition of amino acid signals partitions the cells of the goldfish retina into nine statistically unique biochemical theme classes and permits a first-order chemical mapping of virtually all cellular space. Photoreceptors, bipolar cells, and ganglion cells display a set of unique, nominally glutamatergic type E1, E1 + E2, and E4 signatures, respectively. All horizontal cells are assignable to a GABAergic $\Gamma 2$ class or a non-GABAergic class with a glutamate-rich E3 signature. The amacrine cell layer is largely a mixture of (1) a taurine-dominated T1 Müller's cell signature and (2) GABAergic $\Gamma 1$, glycinergic G1, and dual glycinergic/GABAergic GI1 amacrine cell signatures. Several major conclusions emerge from this work. (1) Glutamatergic, GABAergic, and glycinergic neural signatures and glial signatures account for over $99 \%$ of the cellular space in the retina. (2) All known neurons in the goldfish retina are associated with a set of conventional nonpeptide neurotransmitters. (3) Multiple forms of metabolic profiles are associated with a single nominal neurotransmitter category. (4) Glutamate and aspartate contents exhibit overlapping distributions and are not adequate univariate probes for identifying cell classes. (5) Signatures can serve as quantitative measures of cell state.
\end{abstract}

[Key words: retina, amino acid neurotransmitters, glutamate, GABA, glycine, aspartate, glutamine, taurine, amacrine cells, immunocytochemistry, pattern recognition]

There are 50-100 unique types of neurons in the vertebrate retina (Kolb et al., 1981; Kolb, 1982; Wagner and Wagner, 1988), and most use either glutamate, $\gamma$-aminobutyric acid (GABA), or glycine as a neurotransmitter (Marc, 1985, 1989a, 1992; Yazulla, 1986; Massey, 1990). GABA, glycine, glutamate, aspartate, glutamine, and taurine are the dominant amino acids in the vertebrate retina (Voaden, 1978) and must be partitioned across this cohort of retinal cells. Our goal is to characterize these patterns of amino acid content. This work is an extension of both signature and coexistence hypotheses wherein each unique morphological type of neuron is posited to possess distinctive neurochemical indices (Lam et al., 1980, 1985; Watt et al., 1985; Hökfelt et al., 1987). We now know that neurons express greater biochemical diversity than mere variation in neurotransmitter

\footnotetext{
Received Jan. 19, 1995; revised Mar. 17, 1995; accepted Mar. 21, 1995.

This work was supported by NIH Grants EY02576 (R.E.M.) and EY01406 (S.F.B.), and a Research to Prevent Blindness Jules and Doris Stein Professorship (R.E.M.). We thank Maggie Shaw and Ann Torrence for editorial assistance on parts of this manuscript.

Correspondence should be addressed to Robert E. Marc, John Moran Eye Center, University of Utah Health Sciences Center, 50 North Medical Drive, Salt Lake City, UT 84132.

Copyright (C 1995 Society for Neuroscience 0270-6474/95/155106-24\$05.00/0
}

content. For example, certain regulatory proteins are differentially partitioned within subsets of retinal neurons that apparently use the same amino acid neurotransmitter (e.g., Pasteels et al., 1990; Wässle et al., 1994). Limited analyses of amino acid coexistence have also revealed varied combinations in retinal and central neurons (Marc et al., 1990; Zhang et al., 1991; Crooks and Kolb, 1992; Kritzer et al., 1992; Martin and Grünert, 1992; Kalloniatis et al., 1994; Marc, 1994). In this report, we explore amino acid content in retina using (1) a set of 10 anti-amino acid IgGs as probes of intracellular amino acid levels and (2) pattern recognition methods.

Virtually all prior knowledge of the metabolic properties of neuronal groups has been derived from tissue-level biochemistry, and most of these data imply metabolic homogeneity for a single neurochemical group. However, bipolar cells and ganglion cells express different patterns of amino acid content even though both are presumed glutamatergic cell types. In addition, over $99 \%$ of all retinal space can be formally mapped onto known cell types as glutamatergic, GABAergic, or glycinergic neuronal classes, or as taurine-rich glia. The patterns of aspartate and taurine content lead us to conclude that there are no purely taurinergic or aspartatergic neurons. We have also discovered a type of amacrine cell in the goldfish retina that contains both glycine and GABA, and describe a horizontal cell subset that may be glutamatergic. Finally, we have observed that amino acid signatures are stable under control conditions but neurotransmitter contents can be influenced by light adaptation in some neurons.

\section{Materials and Methods}

Retinal preparations. Retinas were isolated from cervically transected, double-pithed goldfish and either processed immediately for anatomy/ biochemistry or incubated $10 \mathrm{~min}$ at room temperature $\left(22^{\circ} \mathrm{C}\right.$ ) in an oxygenated physiological teleost medium (Marc and Lam, 1981a) prior to fixation in $2.5 \%$ glutaraldehyde in $0.1 \mathrm{M}$ phosphate buffer (pH 7.4) with $1 \mathrm{~mm} \mathrm{Ca}{ }^{2+}$ and $3 \%$ sucrose. Some retinas were incubated in the presence of $1 \mathrm{mM}$ D-aspartate to load glial cells. Most goldfish were dark adapted for 30-60 min prior to death, but all procedures were carried out in room light (control condition). The control immunocytochemical analyses in this manuscript involve over 20 identically processed retinas. Some comparisons of amino acid immunoreactivity in photoreceptors were made in retinas from fully light-adapted animals (adapted to 4-6 hr room light). All animal care procedures meet institutional and Society for Neuroscience guidelines.

Biochemistry. A key to interpreting immunochemical images is knowledge of signal content. Half retinas were isolated free of the retinal pigmented epithelium, flattened onto glass coverslips, macroscopic images captured within $30 \mathrm{sec}$, plunged into liquid nitrogen (selected samples were also weighed), and homogenized in $0.5 \mathrm{ml} 0.1 \mathrm{~N} \mathrm{HCl}$ spiked with $0.4 \mathrm{~mm}$ methionine sulfate as a control. The matching halves were processed for immunocytochemistry. The homogenates were centrifugally microfiltered ( $10 \mathrm{kDa}$ molecular weight cutoff) and derivatized for Pico-Tag amino acid analysis. Four to ten retinas were 


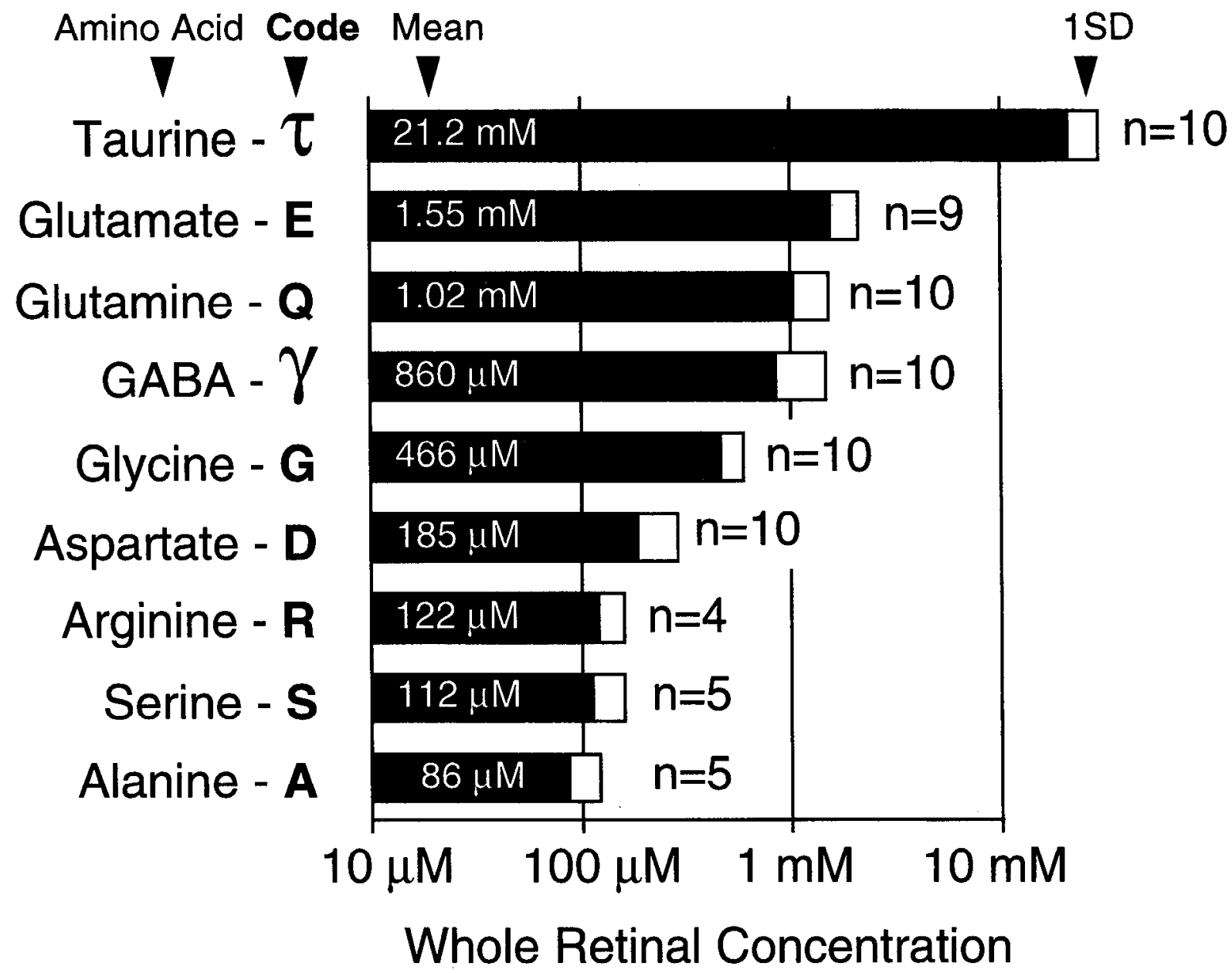

Figure 1. Amino acid concentrations in intact goldfish retina determined by HPLC. Data were collected from half retinas for each amino acid ( $n$ $=4-10$ ), and the matching halves processed for immunocytochemistry. The standard code for the natural amino acids is augmented by Greek symbols $\gamma$ for GABA and $\tau$ for taurine. Abscissa, logarithmic scale; mean indicated on the bar graph; +1 SD indicated by the white cap on each bar.

processed and contents of $27-40$ amino acids measured. It was not possible to remove all adherent vitreous from the goldfish retina in a timely manner which causes variation in weight estimates. However, we can avoid this problem by estimating the retinal volume: areas were measured directly from the calibrated images (including correction for nonsquare pixels) and the mean retinal thicknesses from images of the matching halves corrected for $12 \%$ shrinkage. The amount of adherent vitreous was never more than $20 \%$ of the retinal volume and direct measures of amino acid contents revealed that vitreal concentrations were an order of magnitude lower than retinal levels. Any potential contamination of retinal content estimates by vitreous is far smaller than the variance in retinal data.

Immunochemistry. Amino acid immunogens were prepared as described by Matute and Streit (1986) and Marc et al. (1990) by glutaraldehyde cross-linking the target molecule to BSA, borohydride reduction of part of the sample, mixing unreduced and reduced aliquots, filter sterilization, and storage at $-70^{\circ} \mathrm{C}$. All of our antisera were produced from these immunogens by Berkeley Antibody Company (Richmond, CA) using two to four rabbits per immunogen. Sera were screened and tested for selectivity as described in Marc et al. (1990) with ovalbuminglutaraldehyde-amino acid conjugate test antigens over 6 log unit dilutions. All antisera were selective for their target antigens in biological concentration ranges. Further, IgGs directed against GABA, glycine, glutamate, and taurine were purified by centrifugal E-Z-Sep serum IgG extraction (Middlesex Sciences, Inc., Mansfield, MA) and affinity chromatography on amino acid-derivatized, hydrazide-activated agarose (Pharmacia Biotechnology, Uppsala, SW) with acidic elution. The patterns of immunoreactivity elicited by affinity-purified IgGs were indistinguishable from diluted whole serum.

Nomenclature. A compact notation is necessary to specify test sets and outcomes of analyses. For set definitions we have implemented the conventional single-letter code for the natural amino acids augmented by a Greek notation for the special amino acids (see Fig. 1): alanine = $\mathrm{A}, \gamma$-aminobutyrate $=\gamma$, arginine $=\mathrm{R}, \mathrm{L}$-aspartate $=\mathrm{D}, \mathrm{D}$-aspartate $=$ $\delta$, glycine $=\mathrm{G}$, glutamate $=\mathrm{E}$, glutamine $=\mathrm{Q}$, serine $=\mathrm{S}$, and taurine $=\tau$. Thus a serial section analysis of aspartate, glycine, glutamate, glutamine, GABA, and taurine signals is defined as the DGEQ $\gamma \tau$ sixdimensional set. Strong, binary signal patterns are referred to as GABA, glycine, or glutamate positive and negative: $\gamma \uparrow, \gamma, \mathrm{G}$ I, G , E+, and $\mathrm{E}-$. Characterization of outcomes in terms of theme classes (see Pattern recognition, below) uses a bold, upper-case letter notation for the dominant presumed functional molecules of a cell class and bold ordinal notation for subsets. There are four glutamate-dominated theme classes: E1, E2, E3, and E4; two GABA-dominated theme classes: $\Gamma 1$ and $\Gamma 2$; two glycine-dominated theme classes: $\mathbf{G 1}$ and $\mathbf{G \Gamma 1}$; and one taurine-selective theme class: T1. This is necessary to clearly differentiate between a complex theme class characterized by a mixture of amino acids but dominated by a distinctive molecule (e.g., class $\Gamma 1$ ) and an individual amino acid signal (e.g., $\gamma+$ ).

Immunocytochemistry. All samples were fixed $24 \mathrm{hr}$, dehydrated in graded methanols and acetones, and embedded in Medcast (Ted Pella, Tustin, CA) epoxide resin. Serial vertical, oblique, and horizontal sections were cut at $40 \mathrm{~nm}$ (dark gray) to $1000 \mathrm{~nm}$, depending on cxperimental plan, mounted on HTC 12-spot slides (Cel-Line Assoc., Inc., Newfield, NJ), deplasticized with sodium methoxide, washed in methanol, and rinsed in deionized water prior to air drying. Blocking steps have proven unnecessary. Each section was probed overnight in a humidified chamber with a dilution of whole serum in $1 \%$ goat serumphosphate buffer ( $\mathrm{pH}$ 7.4) calibrated to yield a wide dynamic range of signal strengths over the physiological range of amino acid contents in 


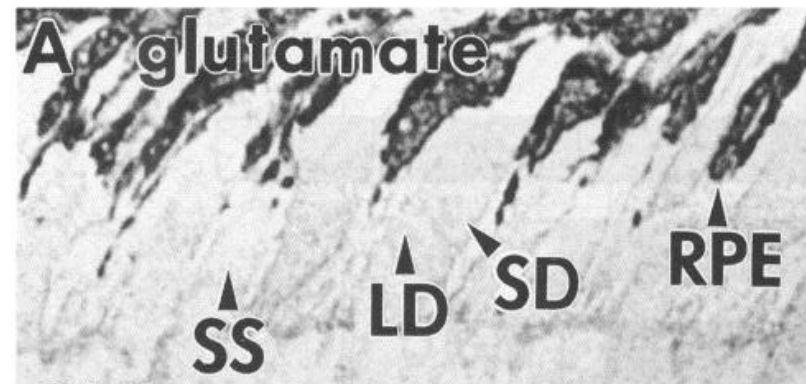

ONL
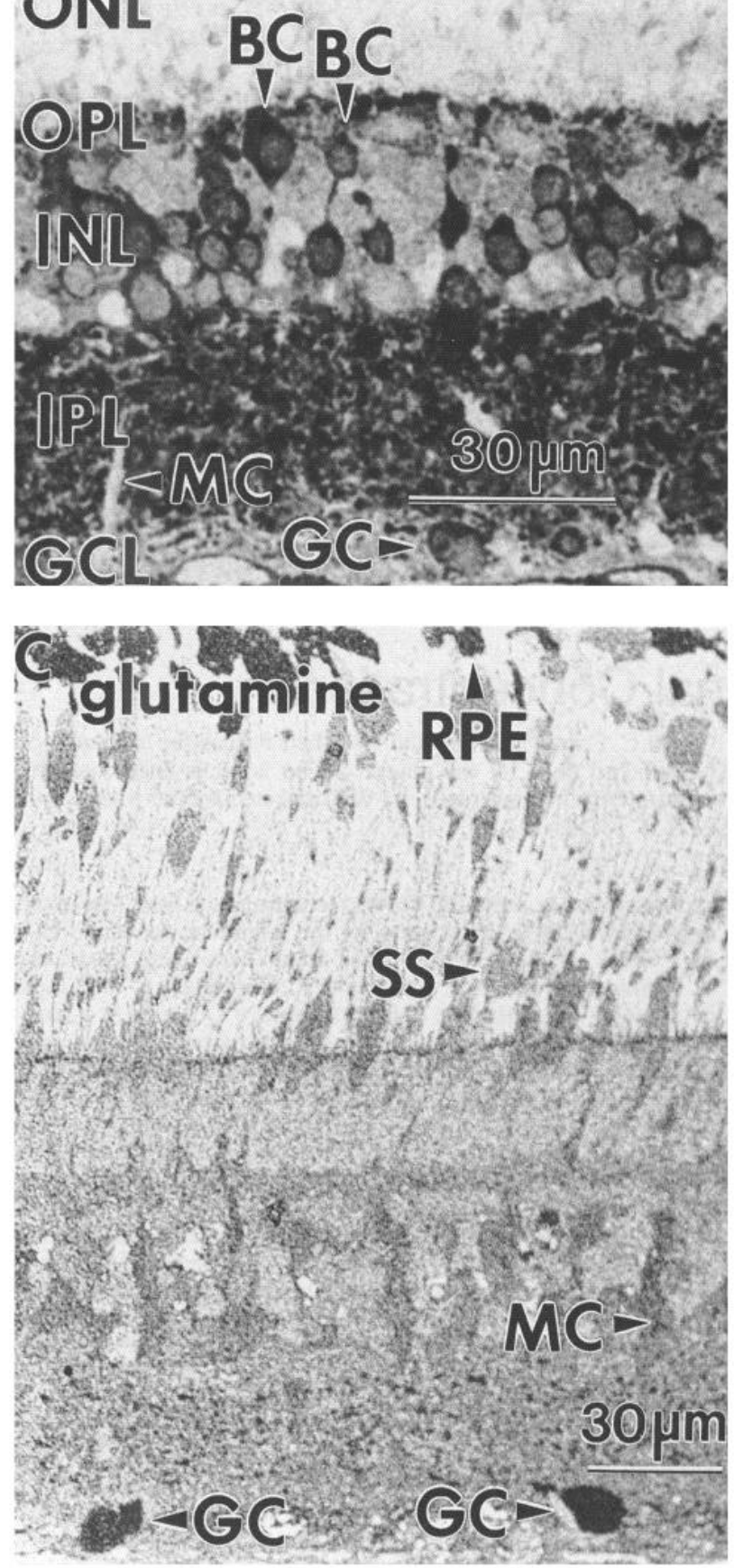
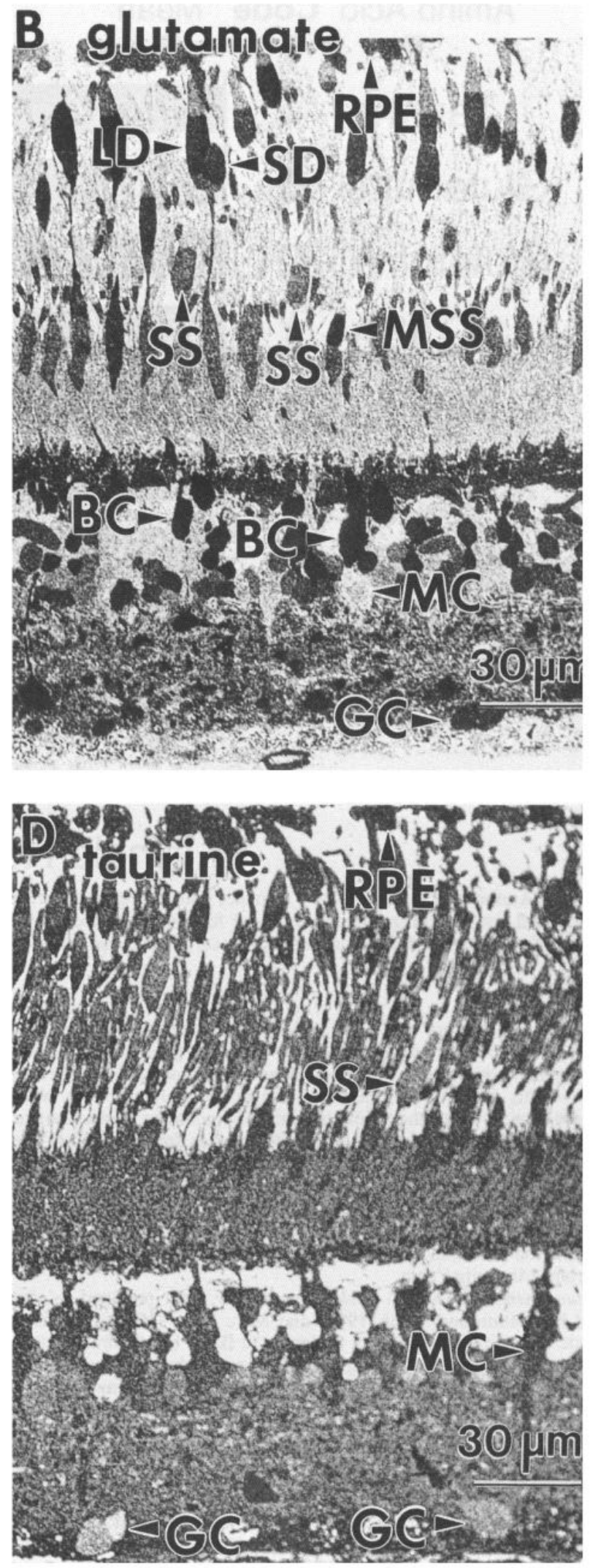

Figure 2. Amino acid immunoreactivity of photoreceptors after light or dark adaptation in the intact goldfish. A, Glutamate immunoreactivity of a retina removed after $60 \mathrm{~min}$ light adaptation (anti-E IgGs 1:4000). There is virtually no immunoreactivity in rods or cones but for weak cone myoid and pedicle signals. However, both the neural retina and the retinal pigmented epithelium $(R P E)$ exhibit strong glutamate signals. $B$, Glutamate immunoreactivity of retina removed after $30 \mathrm{~min}$ of dark adaptation following full light adaptation (anti-E IgGs 1:4000). All cone types are strongly 
retina (anti-A, 1:1000; anti-D, 1:200-1:2000; anti-E, 1:4000; anti-G, 1:2000-1:4000; anti-Q, 1:400; anti-R, 1:200; anti-S, 1:200; anti- $\gamma$, $1: 4000$; anti- $\tau, 1: 4000$ ) or exogenously applied amino acids (anti- $\delta$, $1: 1600$ ). After a $10 \mathrm{~min}$ wash in phosphate buffer, the primary IgGs were localized with goat anti-rabbit IgG coated on $1 \mathrm{~nm}$ gold (Amersham Corp., Arlington Heights, IL) diluted 1:50 in 1\% goat serumphosphate buffer and visualized with silver intensification (Kalloniatis and Fletcher, 1993).

Imaging and pattern recognition. The details of methods for capturing and registering images, visualizing data sets, implementing pattern recognition algorithms, and assessing classification outcomes are provided in the Appendix. In brief, images of amino acid immunoreactivity in retinal sections were captured under standardized conditions and intracellular concentrations estimated as described previously (Marc et al., 1990). Exploring correlations in amino acid content across cell types requires that all immunolabeled sections in a series be accurately registered. This involves identifying a set of common points in all images and calculating the translation, scaling, shear, and rotation of each image required to bring it into alignment with its neighbors. All sets of common points on registered images thus represent lists of amino acid contents associated with a structure in anatomical space. The next problem is to devise a means to explore these lists and search for correlated patterns of amino acid content. One simple way to explore correlations among amino acid contents is to view the images as doublets or triplets by assigning one amino acid image to one color channel of a video monitor. This is amino acid $\rightarrow r g b$ mapping. While useful for visually discovering simple correlations, $r g b$ mapping is not a statistical method and has severe combinatorial limits. However, pattern recognition is a method for detecting and expressing correlations of signals in $N$-dimensional data spaces (Duda and Hart, 1973). A correlated group of signals in $N$-space is known as a theme class and the list of signals associated with it is termed a signature. A theme map is a summary image displaying the distributions of theme classes in the original structure, and we have generated characteristic maps for all neural populations in the goldfish retina. The biochemical signatures underlying theme classes and their statistical properties are explored with scatterplots and histograms. A review of the Appendix is strongly encouraged.

\section{Results}

\section{Biochemistry}

The goldfish retina contains essentially the same array of amino acids as reported for brain tissue of most other vertebrates. Several of the amino acids of interest in this report dominate the free amino acid pool (Fig. 1): taurine, glutamate, glutamine, and GABA comprise over $90 \%$ of the total mass of retinal amino acids. Taurine is the dominant amino acid, ranging from 13 to $35 \mathrm{~mm}$ over the 10 retinas we have analyzed biochemically. Additional amino acids such as cysteine and citrulline also exhibit very high values $(0.6-3 \mathrm{mM})$, but we have not yet characterized their distributions. Alanine, aspartate, arginine, and serine exist at very low retinal levels $(50-200 \mu \mathrm{M})$, but are nevertheless of substantial interest. Alanine is a fundamental amino acid metabolite; aspartate is a precursor to glutamate and presumed ncurotransmitter candidatc; arginine is an intermediate in nitric oxide signaling; and serine is a presumed glycine precursor. Since some or most amino acids may be heterogeneously distributed at the cellular level, a low whole retinal concentration does not necessarily imply that the amino acid has no significant role to play. This is particularly true of glycine (see Marc, 1985), where modest whole retinal and brain levels belie the presence of cells containing extremely high glycine concentrations. Con- versely, a homogeneous distribution of an abundant molecule may imply a common role across multiple cell types. For these reasons, among others, the study of compartmentalization is critical.

\section{Photoreceptor immunocytochemistry}

Rods and cones in the goldfish retina are well segregated cell groups whose signatures may be sampled directly. The volatility of goldfish photoreceptor glutamate signals has been previously described (Marc et al., 1990) and we have unraveled more of the mystery. While cellular glutamate levels are subject to the regulatory influences of oxygen and glucose availability, goldfish cones exhibit great changes in resting glutamate levels dependent on adaptation state. Cones from goldfish that have been light adapted for several hours prior to fixation have essentially no intramitochondrial glutamate signals, weak myoid signals, and maintain only a low level of synaptic glutamate (Fig. $2 A ; n$ $>10$ ). However, when light-adapted fish are dark adapted for $30 \mathrm{~min}$, ellipsoid levels of glutamate rise to 5-10 $\mathrm{mm}$, tracked by myoid levels (Fig. $2 B ; n>15$ ). We currently interpret this effect as a second-order, regulatory response to high rates of glutamate release triggered by short-term dark exposure. Dark adaptation also promotes significant glutamate signals in bluesensitive cones. We previously described blue-sensitive cones as glutamate negative (Marc et al., 1990), but they apparently respond slowly to the adaptation signals. The signature we derive for photoreceptors comes from briefly dark-adapted photopic animals and is statistically identical to that of the primary bipolar cell population (which does not exhibit extreme adaptation-dependent modulation), including glutamine and taurine content (Fig. 2C,D). Taurine levels appear to be so high that even the outer segment possesses significant amounts of immunoreactive amino acid. A more comprehensive analysis of the dynamics of photoreceptor glutamate regulation is in progress, but a major outcome of this investigation is that all photoreceptor types are now associated with a single neurotransmitter candidate: glutamate. While not a primary subject of this report, the retinal pigmented epithelium of the goldfish retina also exhibits a characteristic amino acid composition, with high glutamate (Fig. $2 B$ ), glutamine (Fig. 2C), and taurine (Fig. 2D) signals.

\section{Immunocytochemistry of registered images}

The images in Figure $3 A-E$ are registered digital frames of $\mathrm{EGQ} \tau \gamma$ signals in serial $40 \mathrm{~nm}$ sections of goldfish retina displayed with density scaling (see Materials and Methods). As expected, the highest glutamate signals are present in photoreceptors, bipolar cells, and ganglion cells, while the lowest signals are in Müller's cells (Fig. 3A). Both horizontal cells and a large cohort of amacrine cells express GABA signals (Fig. 3B), and the strongest glycine signals are contained in apparent amacrine cells (Fig. 3C). Glutamine signals are widely distributed, with modest levels in photoreceptors, bipolar cells, Müller's cells, and some amacrine cells. The highest glutamine levels are typically found in ganglion cells (Fig. $3 D$ ), although retinas sam-

glutamate immunoreactive, especially at the ellipsoid level. $C$, Glutamine immunoreactivity of retina removed after 60 min light adaptation (anti-Q IgGs 1:400). Modest immunoreactivity appears in all cone types, but RPE immunoreactivity is notably stronger. Ganglion cells are the most immunoreactive of all retinal cells. $D$, Taurine immunoreactivity of retina removed after 60 min light adaptation (anti- $\tau$ IgGs $1: 4000$ ). $B C$, bipolar cell; $G C$, ganglion cell; $M C$, Müller's cell; $L D$, red-sensitive long double-cone member; $S D$, green-sensitive short double-cone member; $S S$, bluesensitive short single cone; $M S S$, blue/UV sensitive, miniature short single cone; $R P E$, retinal pigmented epithelium; ONL, outer nuclear layer; $O P L$, outer plexiform layer; INL, inner nuclear layer; $I P L$, inner plexiform layer; $G C L$, ganglion cell layer. 

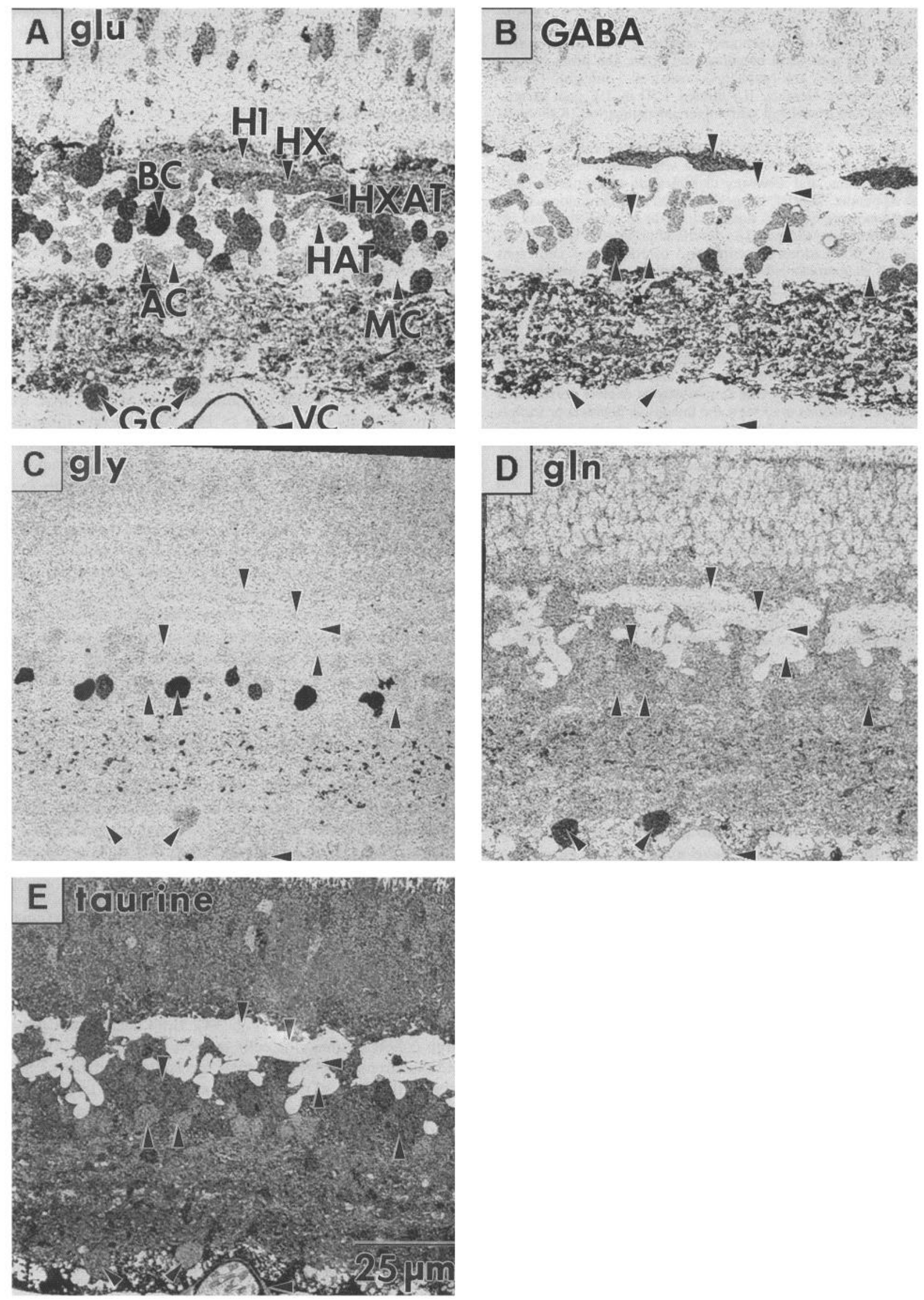

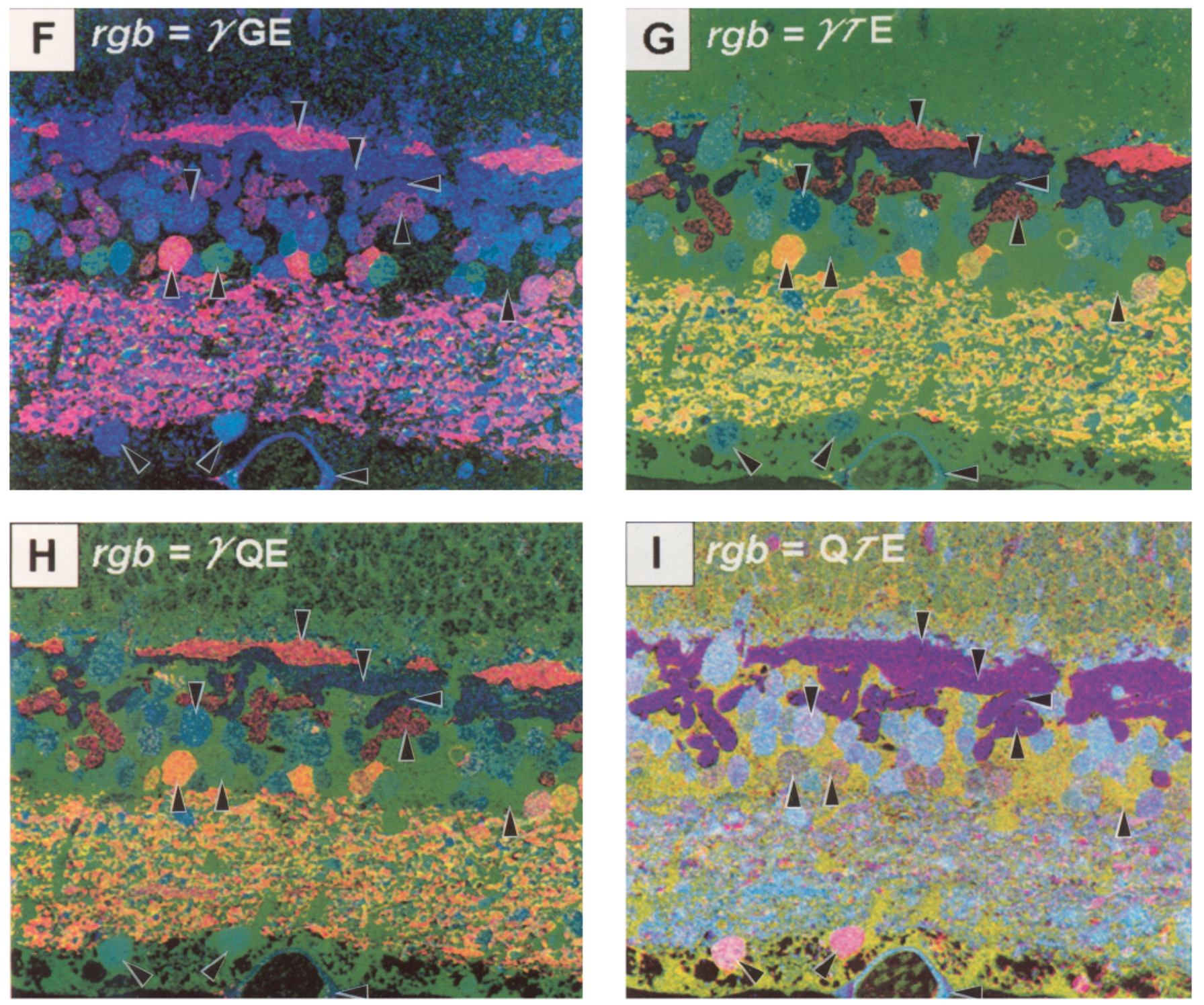

Figure 3. Registered amino acid images of amino acid immunoreactivity in serial $40 \mathrm{~nm}$ sections of goldfish retina. The same bipolar, horizontal (H1, GABAergic; $H X$, non-GABAergic) amacrine $(A C)$, Müller's, ganglion, and vascular cells (VC), and horizontal cell axon terminals (HAT, $H X A T)$ are marked in all nine panels. $A-E$ represent density-scaled images where immunoreactivity is proportional to darkness. $F-I$ are $r g b$ brightness-scaled images where immunoreactivity is proportional to color intensity. A, Glutamate immunoreactivity (anti-E IgGs $1: 4000$ ). B, GABA immunoreactivity (anti- $\gamma$ IgGs 1:4000). $C$, Glycine immunoreactivity (anti-G IgGs 1:2000). Note the weakly glycine-immunoreactive ganglion cell soma. This is a set of ganglion cells not analyzed in this paper; it is not known to be a theme class. $D$, Glutamine immunoreactivity (anti-Q IgGs $1: 500$ ); note the two ganglion cell somas. $E$, Taurine immunoreactivity (anti- $\tau$ IgGs 1:4000). $F$, Superimposed brightness-scaled images yielding the $\gamma \mathrm{GE} \rightarrow r g b$ mapping. $G$. The $\gamma \tau \mathrm{E} \rightarrow r g b$ mapping. $H$, The $\gamma \mathrm{QE} \rightarrow r g b$ mapping. I, The $\mathrm{Q} \tau \mathrm{E} \rightarrow r g b$ mapping.

pled from the high end of the biochemical glutamine distribution in whole tissue content exhibit glutamine signals in Müller's cells nearly equivalent to those of retinal ganglion cells. Glutamine regulation is clearly not static. Finally, taurine signals are extremely strong in most cells except horizontal cells, yielding a nearly binary image (Fig. $3 E$ ). Selecting four of the possible 10 amino acid triplet $r g b$ mappings exposes different signal correlation trends. For example, the $\mathrm{GE} \rightarrow r g b$ (Fig. $3 F$ ) mapping displays the expected partitioning of strong GABA signals into nominally GABAergic horizontal cells and amacrine cells, but the hues are complex and range from rich red through nearly violet, implying diverse mixes of GABA and glutamate. Likewise, glycine-rich cells provisionally termed glycinergic ama- crine cells are a variety of greenish-blue hues, while the blue glutamate signals of bipolar cells, ganglion cells, non-GABAergic horizontal cells, and vascular cells are visually difficult to discriminate from each other. Small ovoid bipolar-like somas with both $\mathrm{E}+$ and $\mathrm{G}+$ signals are also evident (asterisk in Fig. $3 F$ ). Turning to a $\gamma \tau \mathrm{E} \rightarrow r g b$ (Fig. $3 G$ ) mapping provides a strong discrimination of non-GABAergic horizontal cells from both GABAergic horizontal cells and bipolar cells, but reveals a complex spectrum of $\tau \mathrm{E}$ signals through the inner nuclear layer. An alternate selection, $\gamma \mathrm{QE} \rightarrow r g b$ (Fig. $3 H$ ), reveals retinal ganglion cells as glutamine rich and for the first time exposes the fine filigree of presumed Müller's cells processes around rod nuclei in the outer nuclear layer, though it does not clearly dis- 

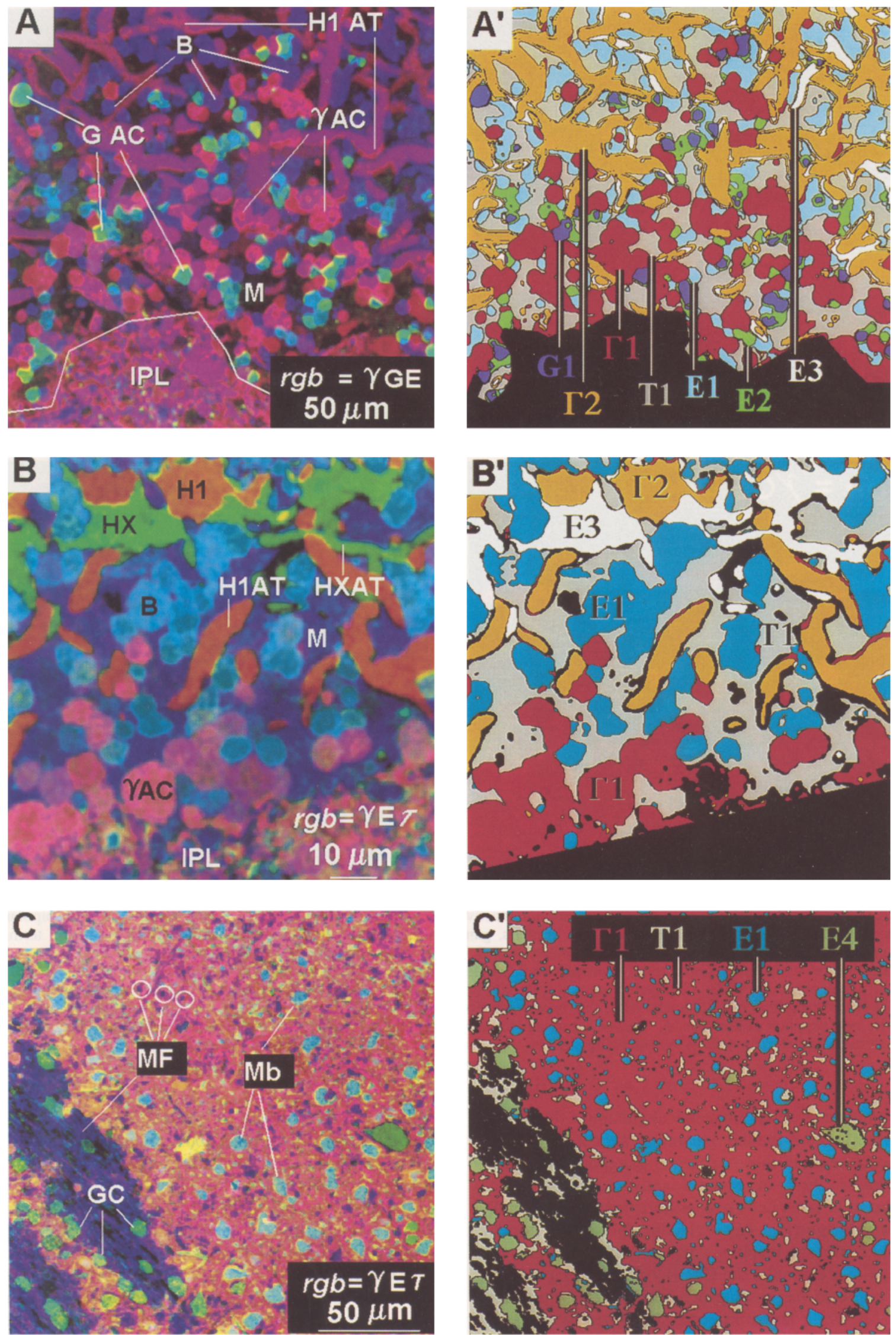

Figure 4. Registered amino acid images of horizontal and oblique sections of goldfish neural retina. The inner plexiform layer was masked off in theme map generation as the spatial resolution of this classification is insufficient to classify neuropil. $A, \gamma \mathrm{GE} \rightarrow r g b$ mapping of the amacrine 
tinguish them from the glutamine signals of bipolar cells. Finally, a $\mathrm{Q} \tau \mathrm{E} \rightarrow$ rgb mapping (Fig. 3I) brings out profiles expected to be Müller's cells (a proposal we will validate below) and distinguishes ganglion cells from bipolar cells, but fails to adequately characterize amacrine cells. It is this tantalizing but visually unmanageable diversity that pattern recognition is designed to resolve. The eye may discern apparent means in signals but cannot decode complex covariances.

\section{Pattern recognition}

Images used for pattern classification were slightly different than those displayed in Figure 3. (1) They were low-pass filtered to attenuate high spatial frequency signals that cannot be registered. (2) They were horizontal and oblique sections containing $200-$ 2000 somas, as pattern recognition requires large fields of data to detect small or rare populations. (3) They were linearly scaled to produce a wide, nonsaturating dynamic range for classification. 'This last tactic is critical for certain weakly dispersed signals. For example, aspartate signals are narrowly dispersed, ranging less than a log unit concentration difference across all cells. Conversely, glutamate signals exhibit high dispersion, ranging from below $100 \mu \mathrm{M}$ in Müller's cells to over $10 \mathrm{~mm}$ in bipolar cells. Linear scaling of all images to the same final PV range effectively normalizes for variance.

The inner nuclear layer is a diffusely laminated somatic cluster, and shallow oblique sections are extremely useful in obtaining large dala samples and defining groups of similar retinal neurons whose layering is not exact enough to define in vertical sections. Figure $4 A$ displays a typical $\gamma \mathrm{GE} \rightarrow r g b$ mapping of amacrine, bipolar, and Müller's cells, and horizontal cell axon terminals. One consistent feature of GABAergic horizontal cells is their weaker GABA signal with respect to amacrine cells. We have observed that horizontal cell immunoreactivity, like that of photoreceptors, is also impacted by adaptation state. Detailed analysis of those data are beyond the scope of this report, but Figure $4 A$ is representative of the typical difference between horizontal cell and amacrine cell GABA signals. As in Figure 3 , a range of hues typifies glycine-rich somas. A large number of cells maps into $\gamma \mathrm{GE}$ space, and GABA and glycine signals are apparently completely separate in this image. There are large gaps in the image which turn out to be strongly glutamine and taurine positive when viewed as the appropriate triplet. However, $r g b$ images are not statistical tools and the hue variations of $r g b$ space connote mappings of amino acid signals too complex for visual decoding. A $K$-means classification of this data set using DEGQ $\tau \gamma$ signals yields seven theme classes with unique biochemical signatures, and each theme class can be color mapped (Fig. 4A'): $\mathbf{1} \mathbf{1}, \gamma+$ amacrine cells; $\mathbf{2}, \gamma+$ horizontal cells; G1, $\mathrm{G}+$ amacrine cells; E1, E+ bipolar cells; E2, E+G+ presumed bipolar cells; E3, $\gamma-$ horizontal cells; and T1, Müller's cells. $D^{T}>1.9$ for all class pairs, indicating robust separation $\left(p_{e}<\right.$ 0.01 ). The theme map of these classifications reveals that the T1 theme class occupies a large fraction of the inner nuclear layer and that the classes segregate along structural lines. This is important as the pattern classification of these cells is based solely on chemical signals and no structural information is encoded in the data set.

There are several novel features of these theme classes that deserve explication. First, the $\mathbf{E 3}$ class in Figure $4 A^{\prime}$ is represented solely by a couple of small glutamate-rich horizontal cell axon terminals in the inner nuclear layer. We have previously reported $\gamma-$ horizontal cell somas and rare $\gamma-$ axon terminals as being glutamate rich (Marc et al., 1990), and in these data the cells are clearly separable from all other glutamate-dominated elements such as bipolar cells. This is more clearly revealed in the $\gamma \tau \mathrm{E} \rightarrow r g b$ mapping of a slightly oblique section through the inner nuclear layer from the inner plexiform layer border to the outer plexiform layer in which $\gamma+$ and $\gamma-$ horizontal cells display their completely different signal compositions in both somas and axons (Fig. $4 B, B^{\prime}$ ). No horizontal cell somas or axon terminals escape classification and are obligatorily assigncd to cither class $\mathbf{\Gamma} 2$ or $\mathbf{E 3}\left(D^{T}=2 ; p_{e} \rightarrow 0\right)$. All distal horizontal cell somas are always $\Gamma 2$ cells and all proximal horizontal cells are always $\mathbf{E 3}$ cells. Finally, a small set of cone horizontal cell axon terminals are of the $\mathbf{E 3}$ type. These observations imply that $\mathrm{H} 1$ horizontal cells are always $\Gamma \mathbf{2}$ cells and that both rod horizontal cells and at least one class of non-H1 cells are $\mathbf{E} 3$ cells.

Both bipolar cells and ganglion cells appear to be glutanatergic, but previous work has suggested that ganglion cells possess amino acid immunoreactivities that differ measurably from bipolar cells (Kalloniatis et al., 1994). Pattern classification of the proximal inner plexiform layer $(\gamma \mathrm{E} \tau \rightarrow r g b$ mapping, Fig. $4 C$; EQ $\tau \gamma$ theme map, Fig. $4 C^{\prime}$ ) displays the axon terminal terminals of $\mathbf{M b}$ bipolar cells as class $\mathbf{E 1}$, ganglion cells as $\mathbf{E 4}$, and the massive GABAergic innervation of the inner plexiform layer as class $\Gamma \mathbf{1}$ pierced by the frequent proximal class $\mathbf{T 1}$ Müller's cell fibers. $\Lambda$ ll of these cells are separable by $D^{T} \geq 1.9$. Glycine signals were omitted from this analysis of the inner plexiform layer. Strong glycine signals were present only in small terminals in the original image and were attenuated by the low-pass filtering used for suppression of kerf. Weak signals did not contribute to any differentiation in this data set.

These data imply that we have classified all cellular space in the goldfish retina, which cannot be completely correct as dopaminergic interplexiform cells comprise $0.5 \%$ of the cell bodies in the amacrine cell layer (Marc, 1982; Van Haesendonck et al., 1993 ) and even less of the planimetric area $\sim 0.3 \%$. In goldfish, dopaminergic interplexiform cells are $\gamma-$ and $\mathrm{G}-$ (Wagner and Wülle, 1990), and their signatures are indiscriminable from Müller's cells even within a full nine-dimensional ADEGQRS $\gamma$ set. If dopaminergic cells could be missed, could not other $\gamma-, \mathrm{G}-$, and $\mathrm{E}-$ cells be submerged in the $\mathbf{T 1}$ signature? We have estimated the upper limit on this error by comparing the areas as-

and proximal inner nuclear layers: $H I A T$, type $\mathrm{H} 1$ horizontal cell axon terminals; $\gamma A C$, amacrine cells; $G A C, \mathrm{G}+$ amacrine cells; $B$, bipolar cells; $M$, Müller's cells. $A^{\prime}$, A theme map of $A$ produced by assigning a map color to each theme class extracted by the $K$-means method (DEGQ $\tau \gamma$ signal set): class $\boldsymbol{\Gamma}, \gamma+$ amacrine cells; class $\boldsymbol{\Gamma}, \gamma+$ horizontal cells; class $\boldsymbol{G} \mathbf{1}, \mathrm{G}+$ amacrine cells; class E1, bipolar cells; class E2, G-rich presumed bipolar cells ; class E3, $\gamma-$ horizontal cells; class T1, Müller's cells. Note that the bright yellow kerf around some G + amacrine cells in $A$, due to a systematic section misalignment, does not corrupt the classifications by theme map. $B, \gamma \mathrm{E} \tau \rightarrow r g b$ mapping of the distal inner nuclear layer: $H 1$, type $\mathrm{H} 1 \gamma+$ horizontal cell somas; $H X$, non-H1 $\gamma-$ horizontal cell somas; $H X A T$, non-H1 $\gamma-$ horizontal cell axon terminals. $B^{\prime}$, The theme map of $B$. Note the presence of both class $\mathbf{E 3}$ horizontal cell somas and axon terminals. $C, \gamma \mathrm{E} \tau \rightarrow$ rg $b$ mapping of the proximal inner nuclear and ganglion cell layers: $G C$, ganglion cells; $M b$, type Mb bipolar cell axon terminals; $M F$, Müller's cell proximal fibers. $C^{\prime}$, Theme map of $C$ : class $\mathbf{E} 4$, ganglion cells. 

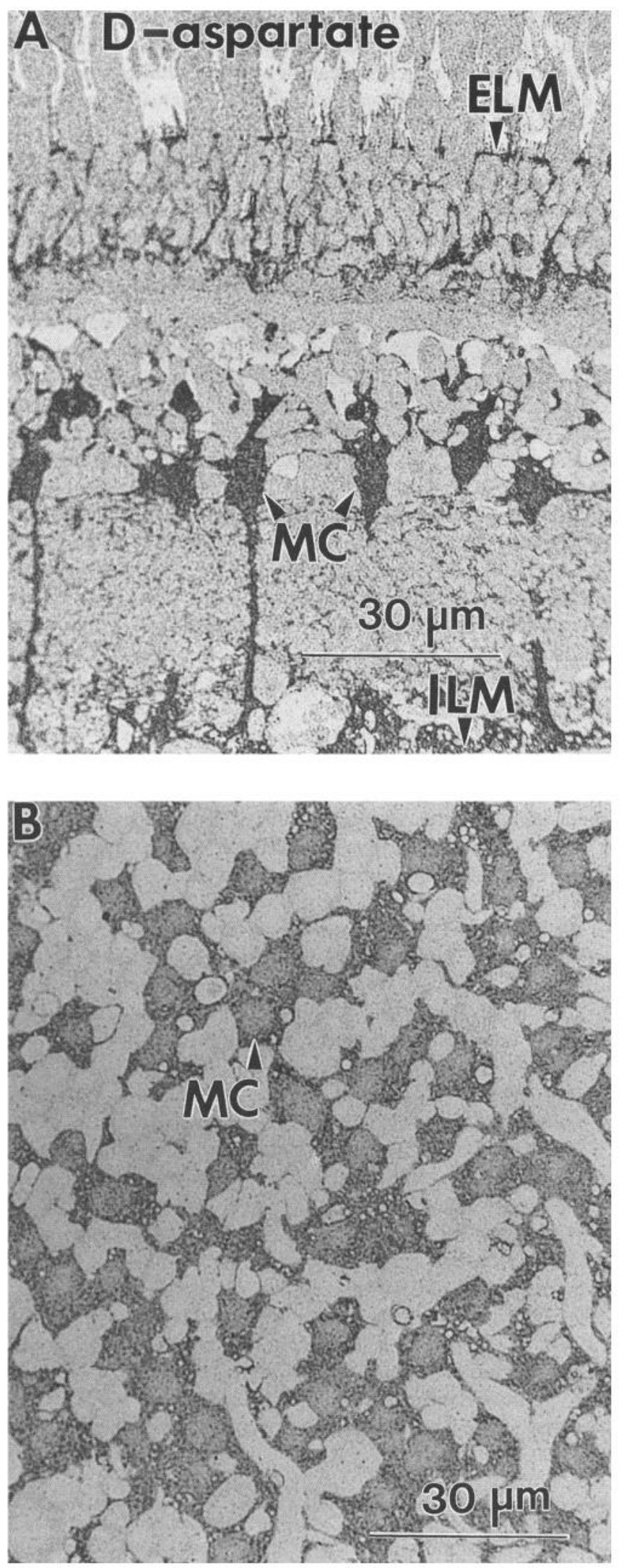

Figure 5. D-Aspartate immunoreactivity in the goldfish retina after preloading for $10 \mathrm{~min}$ in teleost saline containing $1 \mathrm{~mm}$ D-aspartate (anti- $\delta$ IgGs 1:1600). A, Vertical $250 \mathrm{~nm}$ section. Only Müller's cells are labeled. $I L M$, inner limiting membrane; $E L M$, external limiting membrane. $B$, A horizontal $500 \mathrm{~nm}$ section through the amacrine cell signed to the $\mathbf{T 1}$ theme class at any given level of the retina (focusing on the amacrine cell layer) with the actual area taken up by Müller's cells. The latter value was determined from digital images of Müller's cells after loading with D-aspartate (see Materials and Methods) and immunocytochemical visualization with anti- $\delta$ IgGs (Fig. 5). Only Müller's cells are labeled due to their strong spatial buffering and selective transport of L-glutamate, L-aspartate, and D-aspartate (Marc and Lam, 1981b). At the level of the amacrine cell layer, D-aspartate-immunoreactive Müller's cells comprise $23 \pm 4 \%$ of the area (mean $\pm 1 \mathrm{SD}, n$ $=5$ ) and, based on pattern classification, the T1 signature takes up $23.8 \pm 0.5 \%$ of the area $(n=3$, total amacrine cell layer somas sampled $>2000$ ). Thus the area of the T1 signature is indiscriminable from the true Müller's cell area and we would argue that, conservatively, any additional cells hidden under the T1 signature must be no more than the difference between the T1 and mean D-aspartate areas less the contribution of dopaminergic interplexiform cells: $0.8-0.3=0.5 \%$ of the amacrine cell layer area. Considering the variances, that could be effectively zero. At worst, pattern recognition classifies at least $99.2 \%$ of the amacrine cell layer and effectively all other retinal space.

Two minor signatures exist within the field of glycine signals. Most cells have a basal glycine level we estimate to be about $300 \mu \mathrm{M}$, but a subset of small somas with strong glutamate signals has been identified as an E2 class (Fig. $4 B, B^{\prime}$ ) on the basis of its supramillimolar glycine content. The $\mathbf{E 2}$ class is separable from all cells with $D^{T} \geq 1.9$ except class $\mathbf{G 1}$, where the $D^{T}$ is only 1.42 , which is not statistically significant for purposes of pattern recognition. However, the E2 category is significantly different from the $\mathbf{G 1}$ category in classical terms with $P<0.01$ (see Appendix for an explanation of the difference between pattern recognition $p_{e}$ values and classical hypothesis testing). We have not yet determined whether E2 cells are small amacrine cells with exceptionally high glutamate content, a subset of cone bipolar cells with high glycine signals, or a mixture. Some E2 cells exhibit apparent distal processes characteristic of the main dendritic stalks of bipolar cells (Fig. $3 F$ ), are uniformly smaller than the bulk of the G1 class, and have weaker glycine signals than G1 cells. These cells have not been previously identified in the goldfish retina by autoradiography (Marc and Lam, 1981a; Marc, 1982) or immunocytochemistry (Studholme and Yazulla, 1988). Glycine-rich cone bipolar cells are present in çat (Cohen and Sterling, 1986; Pourcho and Goebel, 1987) and other mammals (e.g., Marc and Liu, 1984; Hendrickson et al., 1988; Martin and Grünert, 1992), and presumed glycine-containing bipolar cells of unknown types are present in chondrichthyes, amphibians, reptiles, and avians (review by Marc, 1985).

The other minor signature derives from a single variety of strongly $\mathrm{G}+$ and weakly $\gamma+$ presumed amacrine cell, comprising a GГ1 class of the amacrine cells with $D^{T}=2$. These cells are nicely revealed by constructing $r g b$ images of GABA and glycine immunoreactivity in horizontal sections of the amacrine cell layer, encoding GABA as red, glycine as green, and the coincident cells as blue (Fig. 6). They are extremely sparse (86 cells $/ \mathrm{mm}^{2}$ in a sample of 1573 cells in the amacrine cell layer), are often missed even in horizontal fields (e.g., Fig. $4 A, A^{\prime}$ ), and have not been previously detected in correlated vertical section

$\leftarrow$

layer. Note the similarity between the Müller's cell pattern and the T1 class in Figure $3 A^{\prime}$. 

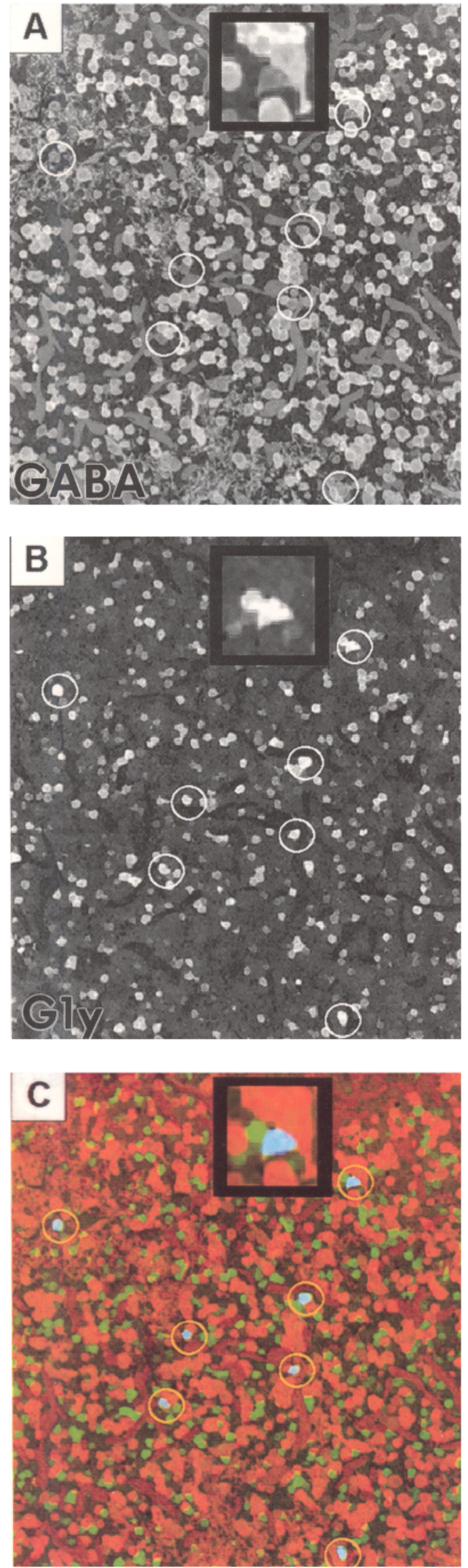

pairs (Studholme and Yazulla, 1988; Marc, 1989b). Goldfish GГ1 cells are about sixfold less frequent than the $\mathrm{G}+\gamma+$ amacrine cells of tiger salamander (Yazulla and Yang, 1988), but the latter population may be complex while the $\mathbf{G \Gamma 1}$ population is apparently singular. The features that define the GГ1 class are the large size of somas, the high glycine content, the modest GABA content, and a surprisingly strong glutamine signal. The GГ1 class might arise from heterologous gap junctions between glycinergic and GABAergic amacrine cells, but we have not found a reciprocal set of cells, a putative class TG1 (high GABA, low glycine) with a different spatial tiling predicted by such a coupling hypothesis. However, if the corresponding GABAergic members of the coupled set were cells with extensive arbors and large net volumes compared to the GГ1 cells, any glycine that leaked into the GABAergic cells may not reach detectable levels even at steady state. In sum, the composition of the amacrine cell layer is complex and the approximate fractions of the layer comprised by different cell types are as follows: $\boldsymbol{\Gamma} \mathbf{1}$ amacrine cells, $30 \% ; \boldsymbol{\Gamma} \mathbf{2}$ horizontal cell axon terminals, 20\%; G1 + GГ1 amacrine cells, 5\%; E2 +E4 cells, $12 \%$; T1 Müller's cells (including dopaminergic interplexiform cells), $24 \%$ ( $n \sim 1500$ registered, classified cells). The remaining $4 \%$ in this sample was unclassifiable kerf. It is likely that these values can shift from region to region but are probably always close to $1 / 3$ GABAergic amacrine cells, 1/5 GABAergic horizontal cell axon terminals, 1/4 Müller's cells, and the remainder a mix of bipolar and glycinergic amacrine cells. The multimodal nature of glycine immunoreactivity (see below) reveals that previous estimates of glycinergic "amacrine cells" (Marc, 1982) are likely a mix of E2, G1, and GГ1 cells. Moreover, both including and excluding E2 cells from the glycinergic cohort indicates that GABAergic amacrine cells comprise from $70 \%$ to $85 \%$ of "true" amacrine cells, but much less of the entire amacrine cell layer.

\section{Probability density distributions}

Mapping $N$-dimensional data theme classes into anatomical space is not an end in itself. Our objectives also include exploring relations among amino acid probability density distributions across classes, thereby drawing inferences regarding the fundamental biochemistries underlying neurochemical homeostasis. Binary masking of classes to reveal their underlying signal histograms (Marc et al., 1990) is a special and limited form of analysis, whereas pattern recognition based on statistical decision boundaries is the corresponding formal and general means of class masking. Figure $7 A$ is a bivariate map of classes probed with GABA and glycine signals across cell types in the inner

$\leftarrow$

Figure 6. Registered $\gamma \mathrm{G}$ images of $250 \mathrm{~nm}$ horizontal sections through the amacrine cell layer. The circles localize class GГ1 cells exhibiting high glycine and modest GABA immunoreactivity. The inset shows an enlarged patch from the upper right circle. A, GABA immunoreactivity. Note the medium size and modest immunoreactivity of the $\mathbf{G \Gamma} \mathbf{1}$ cells. $B$, Glycine immunoreactivity, where the $\mathbf{G \Gamma 1}$ are clearly the brightest and largest cells, forming a sparse array. $C$, A $\gamma \mathrm{G}[\gamma \wedge \mathrm{G}]$ $\rightarrow r g b$ mapping. The pure red signals represent pure $\gamma+$ amacrine cells and horizontal cell axon terminals, and pure green signals represent pure $\mathrm{G}+$ amacrine cells and perhaps some E2 cells. Coincident $\gamma+$ and $\mathrm{G}+$ signals were enhanced by extracting those signals alone with logical AND operation $(\gamma \wedge G)$ and assigning that image to the blue gun. Thus cells with strong $\gamma+$ and $\mathrm{G}+$ signals appear white. 
Figure 7. Bivariate class probability density distributions. The axes represent the scaled amino acid signal strengths, and the ellipses are the 2 SD limits of a bivariate Gaussian source for each theme class. $A, \gamma \mathrm{G}$ signal densities from Figure $4 A$. The dense bands represent the highest frequencies of anatomic pixels mapping to a given $\Gamma G$ coordinate; for clarity, individual pixels represented by single instances of a value pair are not mapped. All $\gamma \mathrm{G}$ signals from the six-dimensional DEGQ $\tau \gamma$ space are thus collapsed onto the bivariate plane. An elongated cloud includes both class $\boldsymbol{\gamma} \mathbf{1}$ amacrine cells $(\gamma+A C s)$ and class $\mathbf{\Gamma} 2$ horizontal cells $(\gamma+H C s)$, although the spur of separate, narrowly dispersed $\gamma$ signals representing $\gamma+$ horizontal cells is distinct. The $\mathbf{G 1}$ class $(G+A C s)$ represents a separate population of amacrine cells, and the composite $\gamma-\mathrm{G}-$ mode contains most other elements, that is, class E1, E3, and T1 cells. There are two additional theme classes representing very small cell populations. We tentatively presume that E2 cells are bipolar cells based on structural inferences, but they possess significant $G$ signals. They are statistically separate from all classes except G1, as is evident from the overlap on the glycine axis $\left(D^{T}=1.42, p_{e}>0.05\right)$. The statistically and structurally unique $\mathbf{G \Gamma} \mathbf{1}$ cells are not present in Figure $4 A$, but the ellipse for the theme class derived from samples is superimposed for clarity. A numerically small population, their variances are rather high, but still separate from all cell types $\left(D^{T} \geq 1.9\right.$ for all comparisons, $\left.p_{\varepsilon}<0.01\right)$. $B$, ED signal densities from Figure $4 A$. As the glutamate-aspartate data clouds overlap extensively, pixel densities have been excluded from the image and only the 2 SD ellipses displayed. This plot demonstrates extensive overlap of signals, especially on the glutamate axis, and emphasizes that $\gamma+$ and G+ amacrine cells can contain as much glutamate as bipolar cells. The cells of the inner nuclear layer with the highest aspartate content are $\gamma+$ amacrine cells.

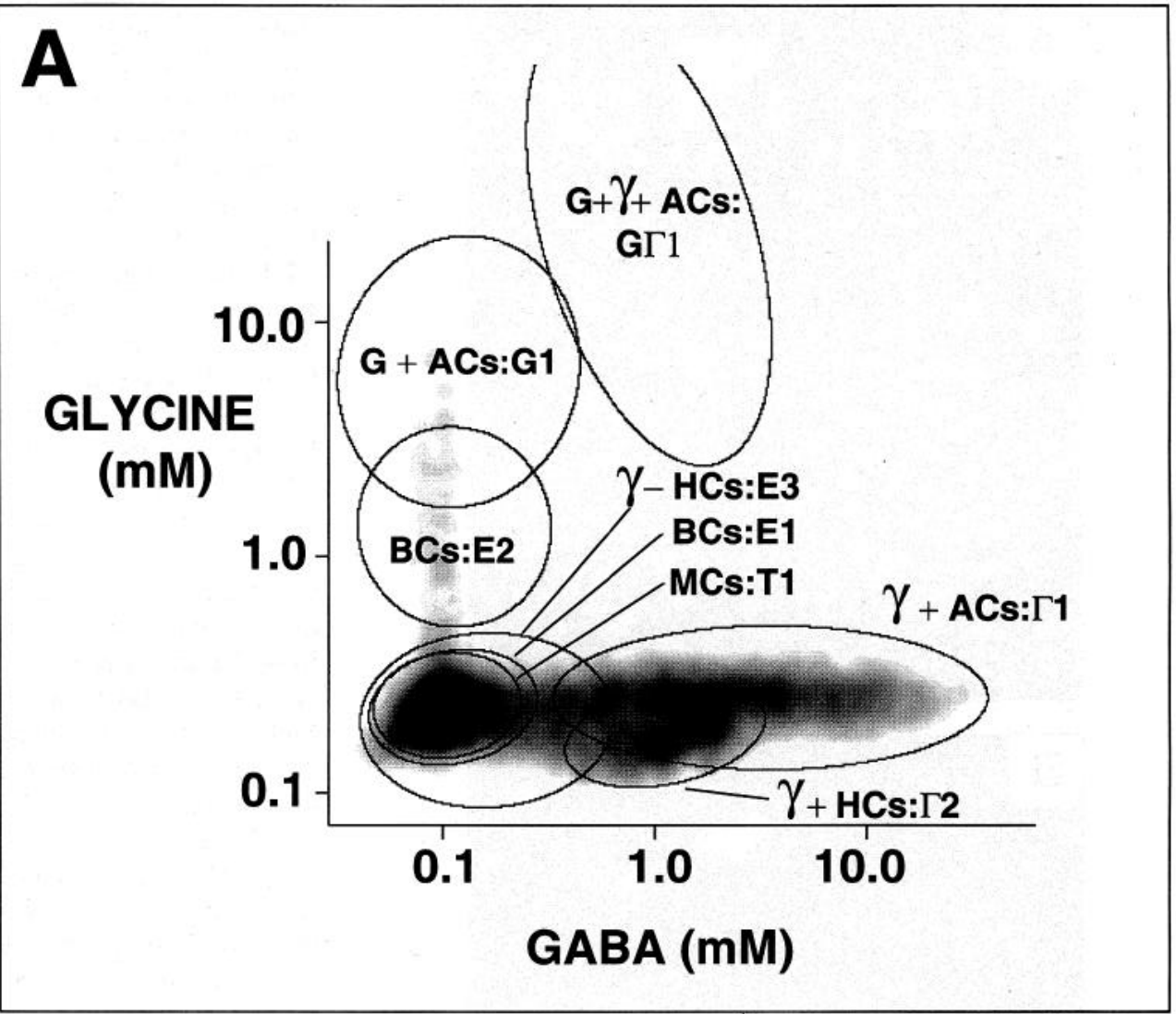

B

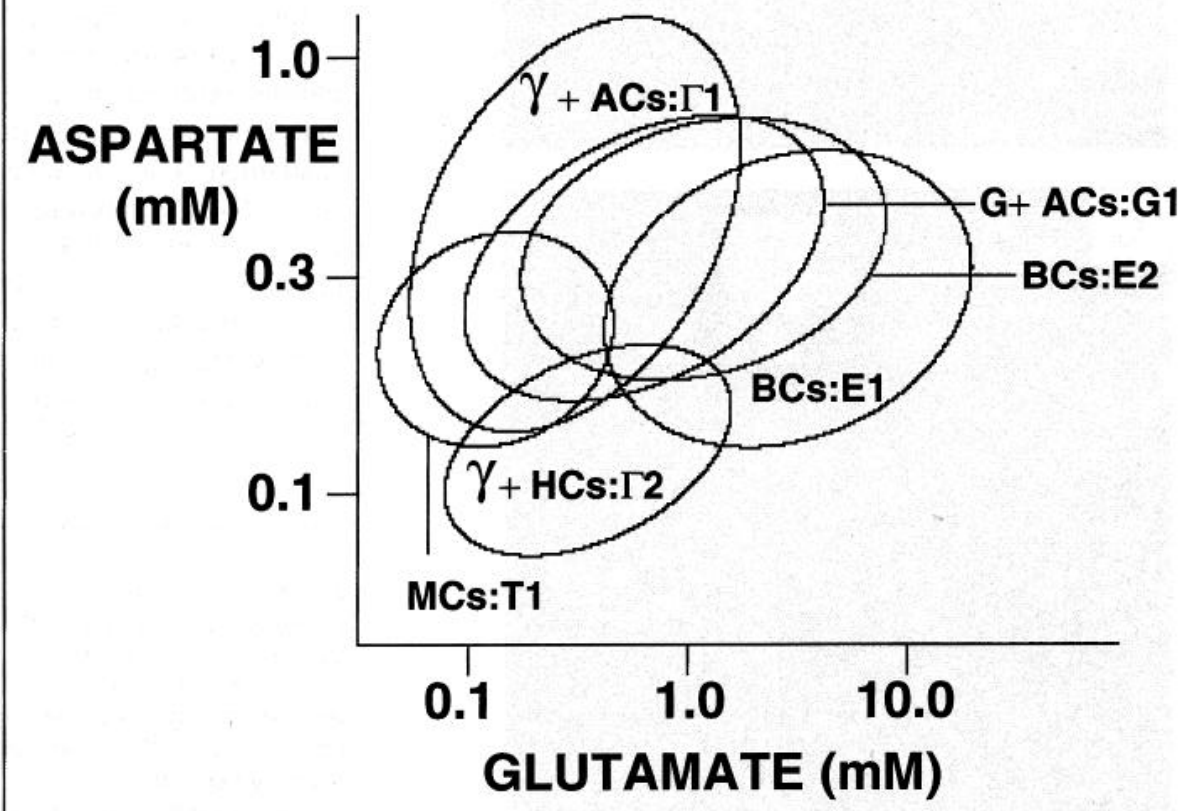


nuclear layer, and is derived from Figure $4 A^{\prime}$. The clouds of data points represent the scaled densities of pixels in the original $N$-channel image that exhibit particular combinations of signals in the GABA and glycine vectors: the darker the cluster, the higher the density of correlated pixels. Many values are forbidden and the data stream nearly orthogonally along the two axes. The values near the origin represent those data that constitute the background $\left(\gamma-, \mathrm{G}^{-}\right)$signals. A large $\gamma+$ cloud along the axis represents both amacrine cell and horizontal cell signals, whereas the most distant $G+$ cloud along the $G$ axis represents amacrine cells. A key point is that dispersions of $\gamma+$ signals in the $G$ dimension and $G+$ signals in the $\gamma$ dimension are very narrow and indiscriminable from background. This is the formal evidence that high levels of GABA and glycine do not coexist in most cells, and defines the $\gamma+$ versus $G+$ decision boundaries among clusters. Superimposed upon the raw data are the singleclass ellipsoids for each theme class: the centroids represent the bivariate signal means and the boundaries are the 2 SD limits for the data in that class. The ellipses of classes $\Gamma 1$ and $\Gamma 2$ (GABAergic amacrine cells and horizontal cells, respectively) quantify the visual observation that horizontal cells are less GABA immunoreactive than most amacrine cells, yet have significant overlap. This illustrates the power of pattern recognition, for the chemical definitions of $\Gamma \mathbf{1}$ and $\Gamma 2$ classes are derived from a six-dimensional DEGQT $\gamma$ set with $D^{T}=2$ for this pair. This is a particularly simple case since most of the statistical separation in this comparison derives from the taurine signal; conversely, the separation of $\mathbf{\Gamma 2}$ and $\mathbf{E 3}$ classes $(\gamma+$ and $\gamma-$ horizontal cells) is not possible in the taurine dimension and derives, rather, from a combination of glutamate and GABA signals. Thus the bivariate plots reveal the extent to and ways in which statistically separable classes segregate or overlap along various signal dimensions. Within the $\gamma \mathrm{G}$ field, E1 bipolar cells, E3 horizontal cells, and T1 Müller's cell signals fully overlap while a narrow cloud of $G$ signals branches off and is separable into $\mathbf{G 1}$ amacrine cells and presumed E2 bipolar cells. The weak $G$ scatterplot signal derives from the relative infrequency of glycine-rich cells relative to GABAergic amacrine cells. Though there were no class $\mathbf{G \Gamma 1}$ cells in the field represented by Figure $7 A$, the single-class ellipse for $\mathbf{G \Gamma 1}$ cells is indicated on the plot.

Unlike GABA and glycine, other amino acids such as the set DEQT have graded, varied distributions across cell classes and the visualization of bivariate spaces can provide special insights regarding their relationships. Many models of neurotransmission and neuronal metabolism imply obligate relations among aspartate and glutamate pools or glutamine and glutamate pools (Hamberger et al., 1979a,b; Shank and Aprison, 1979; Altschuler et al., 1981; Shank and Campbell, 1984a,b; Kvamme et al., 1985; Palaiologos et al., 1989). Fxplorations of ED space (Fig. $7 B$ ) are thus of considerable importance for kinetic reasons. Clouds of raw data points are complex, overlapping, and of little use in analyzing classes and we instead display the relevant single-class ellipses. Class E1 bipolar cells are thought of as typical glutamatergic cells and, though their glutamate signals are among the highest of all ectotherm retinal neurons (Ehinger et al., 1988; Marc et al., 1990; Van Haesendonck and Missotten, 1990, 1991; Kalloniatis and Fletcher, 1993), they have surprisingly low aspartate levels compared to many other retinal cells. The highest aspartate levels in the inner nuclear layer are actually found in a subset of class $\Gamma \mathbf{1}$ amacrine cells. This signature subset pattern in $\Gamma \mathbf{1}$ is not strong enough to lead to resolution of a statistically separate class (see below), but is nonetheless a unique feature of the $\Gamma 1$ cell class relative to all other classes. Even so, the aspartate-rich amacrine cells are clearly a unique set of amacrine cells. Thus, a high aspartate signal does not necessarily imply excitatory function in goldfish retinal neurons and there are no purely aspartatergic cells. The ED signature of $\mathbf{I} \mathbf{1}$ amacrine cells is largely segregated from that of bipolar cells, but if one considers the marginal distributions of both systems, the univariate overlap is substantial on the D axis and small but significant on the $\mathrm{E}$ axis. ED signals thus covary in segregated patterns for $\Gamma 1$ and E1 cells. Though some GABAergic amacrine cells may occasionally display glutamate signals as high as some bipolar cells, they remain a metabolically unique set of cells with a completely separate D covariance.

The fine structures of univariate signatures can be as informative as bivariate plots, but with unavoidable loss of covariance information. Thus we can examine the detailed relationships of amino acid contents across classes for the DEGQ $\tau \gamma$ set (Fig. 8A-F). Univariate histograms were generated as Gaussian envelopes (see Appendix) for clarity and as tests of the validity of using transformed divergence. Figure $8 \mathrm{~A}$ shows the excellent correspondence between the Gaussian fit and the raw glycine signals.

Glycine (Fig. 8A). As indicated in Figure 7A, all glycine signals arc compartmentalized into three modes: (1) a narrowly dispersed, global signal centered on roughly $300 \mu \mathrm{M}$ which we believe represents the basal level of glycine in all cells; (2) a 1$3 \mathrm{mM}$ peak associated with E2 cells; and (3) a discrete highglycine peak centered around $10 \mathrm{~mm}$ derived from class G1 amacrine cells. Not shown on this plot (but see Fig. 10) is the GN1 class, which has the highest glycine levels of all retinal cells. Note that the overlap of G1 and E2 signatures far exceeds $10 \%$, which accounts for the low $D^{T}$ of this pair of classes. The failure of a given set of signatures to provide statistically significant separation for a pair of presumed classes does not mean that the classes must be merged. On the contrary, the segregation implies that a search for a more robust separator may be successful. Indeed, the shapes of $\mathbf{E 2}$ cell somas closely resemble cone bipolar cells, as noted previously. Shape is a higher-order descriptor which we have not yet included in our pattern recognition protocols

$G A B A$ (Fig. $8 B$ ). Consistent with the heterogeneous nature of the GABAergic amacrine cell population, the probability density function for $\Gamma 1$ cells is clearly multimodal, containing both high and modest GABA levels. Conversely, the distribution for $\mathbf{\Gamma} 2$ horizontal cells, a very homogeneous group, is unimodal and has less dispersion. Virtually all other cells are represented by a single peak at nominal background levels, and contain no measurable GABA. Not shown on this figure (but see Fig. 10) is the GГ1 group which displays GABA levels at the low end of all GABAergic amacrine cell signals.

Glutamate (Fig. 8C). Glutamate histograms are dispersed over a $0.1-10 \mathrm{~mm}$ range with bipolar and ganglion cells having the highest mean and limiting levels. The multimodal signal dispersion of the $\mathbf{E 1}$ bipolar cell theme class actually arises from summation of signals from bipolar cell subclasses (e.g., types Ma and $\mathrm{Mb}$ mixed rod-cone bipolar cells and certain pure cone bipolar cells; see Ishida et al., 1980; Sherry and Yazulla, 1993). The glutamate signals of the $\mathbf{E 2}$ class that we presume may be cone bipolar cells are centered on the low end of the class E1 mode. Since the smallest bipolar cells seem to possess the weakest glutamate signals within the class, cone bipolar cells may 

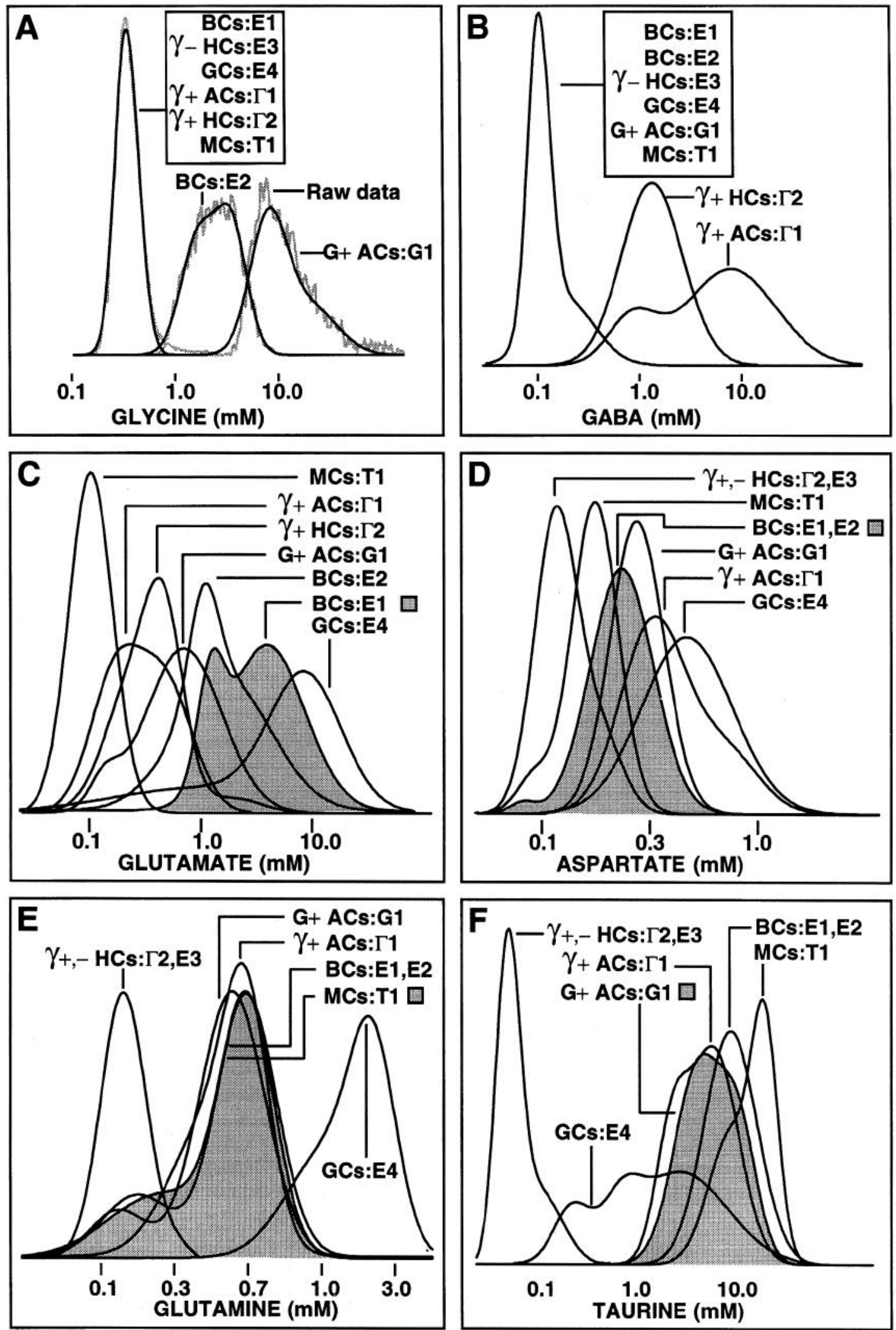

Figure 8. The fundamental univariate amino acid probability density distributions for all theme classes. The abscissas are scaled to calculated intracellular concentrations and each set of ordinate values is integral normalized so that relative amplitude reflects dispersion $\left[\int_{0}^{*} p(c) d c=1\right.$ where $p(c)$ is the probability of encountering a given concentration]. Absolute numerical ordinate values are thus irrelevant. Data signals for each amino acid in each theme class were fitted as linear Gaussian sum envelopes $(r>0.95)$. Secondary modes represent multimodal populations except where identified as kerf artifacts or nuclear signals. For clarity of display, the GГ1 class is omitted from this figure but is included in Figure 10 . A, 
produce these lower signals in general. Due to their large sizes, the terminals of $\mathrm{Ma}$ and $\mathrm{Mb}$ bipolar cells can be sampled directly and, under control conditions, each subclass possesses a unique, narrow-band glutamate signature (Fig. 9A) with OFF center $\mathrm{Ma}$ bipolar cells exhibiting consistently higher $\mathrm{E}$ signals. This pattern can change with light adaptation status, but $\mathrm{Ma} / \mathrm{Mb}$ populations under our conditions can apparently maintain a stable 2$3 \mathrm{~mm}$ difference in mean glutamate content. Other theme classes or class subsets display similar narrow-band glutamate dispersions, for example, displaced $\gamma+$ amacrine cells (not shown) and class E3 horizontal cells. $\Gamma 1$ and $\Gamma 2$ neurons clearly contain glutamate levels that are close to the $K_{d}$ of glutamic acid decarboxylase (GAD; 300-700 $\mu \mathrm{M}$; Wu, 1976; Martin, 1987), but we have no explanation for the surprisingly high glutamate content of certain $\mathbf{G} \mathbf{1}$ amacrine cells, which exceeds that of $\Gamma \mathbf{1}$ cells and overlaps bipolar and ganglion cell glutamate signals. Because of this overlap, any solitary signal such as glutamate alone may have a high $p_{e}$ for cell classification, especially by electron microscopy. Certain members of GABAergic and especially glycinergic amacrine cell populations possess glutamate signals that surpass those of some bipolar cells. These cells are otherwise statistically impossible to discriminate from bipolar or ganglion cell profile labeling in the absence of other diagnostic cytologic features. This is an intrinsic risk associated with the use of single probes with overlapping class strengths, which may be remedied by adding a highly divergent signal (such as $\mathrm{G}$ or $\mathrm{Q}$ in this case) to the data set, which can render $p_{e} \rightarrow 0$. For clarity, the $\boldsymbol{\gamma}-\mathbf{E 3}$ horizontal cells are not included in this univariate signature set (see Fig. 10). In most preparations, ganglion cell glutamate signals, class $\mathbf{E 4}$, are equal to or higher than bipolar cell signals. However, portions of the E1 bipolar cell set in some $25 \%$ of the over 20 retinas analyzed in this study had higher glutamate levels than ganglion cells. In all retinas, Müller's cells always displayed no detectable glutamate signals $(<0.1 \mathrm{~mm}$ ).

Aspartate (Fig. $8 D$ ). Aspartate signals are $0.1-0.5 \mathrm{~mm}$ in most cells. The highest retinal aspartate levels are found in a subset of $\gamma+$ amacrine cells. These levels exceed the aspartate signals in most ganglion cells, and perhaps explain the presence of aspartate aminotransferase immunoreactivity in some amacrine cells (Altschuler et al., 1982) and reports of aspartate immunoreactivity in turtle amacrine cells (Yaqub and Eldred, 1991). However, no purely aspartergic neurons exist in the goldfish retina and any hypothetical aspartergic cotransmission must originate from GABAergic amacrine cells. The aspartate-rich $\gamma+$ amacrine cell population can thus be partially resolved by (1) further decomposition of aspartate signals (Fig. 9B) and (2) submasking by thresholding to select only those pixels associated with the highest Gaussian. Submasking revealed that high as-

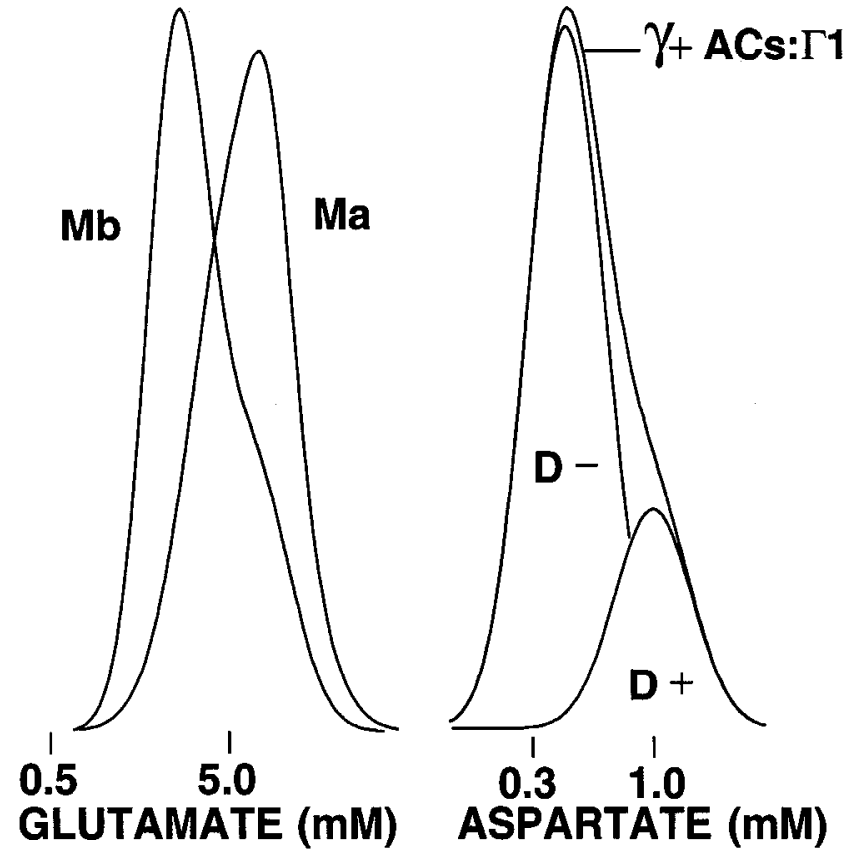

Figure 9. Decompositions of probability density distributions. Left, Partial decomposition glutamate signals derived from class E1 bipolar cells. Between 50-100 axon terminals of the $\mathrm{Ma}$ and $\mathrm{Mb}$ bipolar cell subclasses were sampled from the inner plexiform layer of a light-adapted retina, scaled, and integral normalized. Under these conditions, Ma bipolar cell terminals are more strongly immunoreactive than $\mathrm{Mb}$ terminals. Right, Partial decomposition of the class $\Gamma 1$ amacrine cell aspartate signature. The full signature was decomposed by least squares modeling into the smallest number of Gaussians required to generate a fit of $r>0.99$, yielding low-aspartate $\mathrm{D}-$ and high-aspartate $\mathrm{D}+$ modes. The $\mathrm{D}+$ group corresponds to the amacrine cells shown in Figure $11 A$.

partate values were associated with subsets of $\gamma+$ cells rather than a distribution of subcellular high aspartate values across all cells, and this is particularly evident in aspartate immunoreactivity patterns in the amacrine cell layer (see Fig. 11A). The aspartate-rich group does not appear to be a single amacrine cell variety, however. Bipolar and ganglion cell aspartate signals indicate that relatively small aspartate pools are associated with a large glutamate pool in goldfish and, further, that the absolute relations among aspartate and glutamate signals are clearly heterogeneous across nominally glutamatergic neurons. No single metabolic model can account for all forms of glutamatergic neuron signatures.

Glutamine (Fig. 8E). As a major carbon source for glutamate synthesis (e.g., Hamberger et al., 1979a; Kvamme et al., 1985),

$\leftarrow$

Glycine. Glycine signals in G1 and E2 cells form two separate modes, and all other cells collapse into a single mode centered at about $300 \mu \mathrm{M}$ glycine. The raw data signals are shown as gray traces and the Gaussian fits in black. In all other panels, the raw data are omitted as the simpler Gaussian profiles properly depict theme class properties. B, GABA. Signals in $\Gamma 1$ amacrine cells are multimodal, with the lower mode strongly overlapping with $\Gamma 2$ horizontal cell signals. All other cells possess signals around $0.1 \mathrm{~mm}$, which is background. The foot on the non-GABA mode is uncorrected kerf. $C$, Glutamate. Glutamate signals range from background levels in class T1 (Müller's cells) through about 10 mm in E4 (ganglion cells) and the upper mode of class E1 (bipolar cells). The dual modes of the E1 class represent a mixture of Ma, Mb, and cone bipolar cell signals. $D$, Aspartate. The upper limit of aspartate values for most goldfish retinal cells is less than $1 \mathrm{~mm}$. The mean class E4 (ganglion cell) signal is $0.5-$ $0.7 \mathrm{~mm}$. There is a strong shoulder on the probability density function of $\Gamma \mathbf{1}$ amacrine cells that represents a small class of high aspartate cells (see Figs. 9, 11). E, Glutamine. The glutamine profile of the retina is trimodal, with all horizontal cell types (class $\mathbf{\Gamma} 2 \gamma+$ and $\mathbf{E} \mathbf{1}-$ horizontal cells) possessing no measurable glutamine, most other cells clustered around $0.7 \mathrm{~mm}$, and class $\mathbf{E} 4$ (ganglion cells) distinctively labeled at between 1 and $3 \mathrm{~mm}$. The secondary modes on most cells represent nuclear signals. The classes formed by such signals are merged in generating theme class maps (Fig. 3), but they are never lost from the data set and may always be examined quantitatively. $F$, Taurine. Most cellular taurine signals exceed $5 \mathrm{~mm}$ except for classes $\mathbf{\Gamma 2}$ and $\mathbf{F . 3}$, which are effectively zern, and class $\mathbf{E} \mathbf{4}$, which exhibits a complex population of signals we have not yet decomposed. 


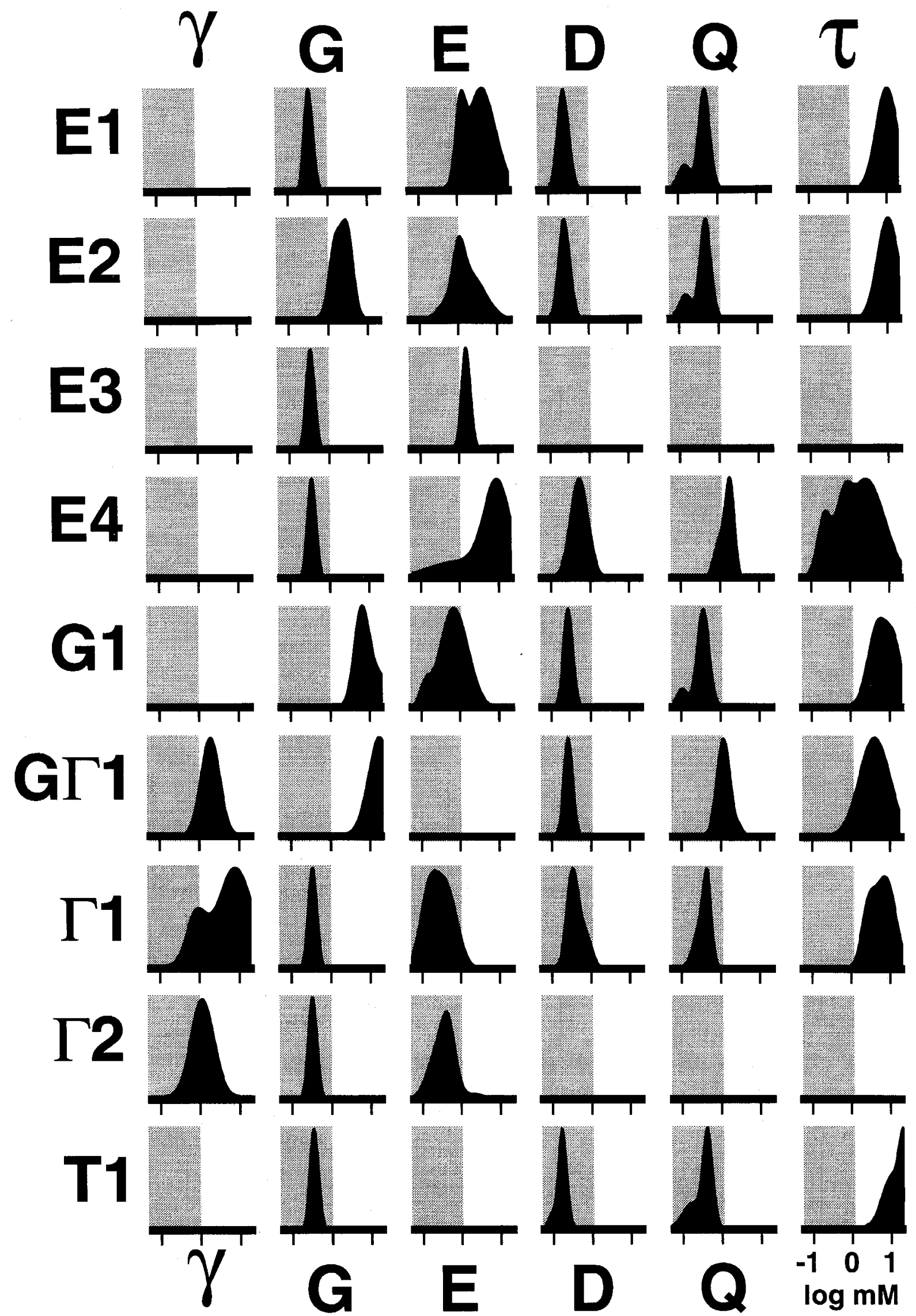


glutamine has the potential for defining glutamatergic signatures. Surprisingly, most glutamine in the retina is equally concentrated in bipolar cells, glial cells, and inhibitory amacrine cells, and thus glutamine content does not define an excitatory neuron. Approximately $0.7-1 \mathrm{mM}$ glutamine signals map to Müller's cells, which clear glutamate from the extracellular space (Marc and Lam, 1981b; Brew and Attwell, 1987; Attwell and Mobbs, 1994) but lack any significant intracellular glutamate signal (Marc et al., 1990). This implies that glutamine synthetase in retinal glia rapidly converts glutamate (Riepe and Norenburg, 1977; Marc et al., 1990; Pow and Robinson, 1994) and that one slow stage in the glial component of the multicellular glutamate cycle is likely glutamine efflux, similar to most but not all brain glia (Pow, 1993). The highest neuronal glutamine levels (3 mM) are found in ganglion cells, while the bipolar cells contain only submillimolar signals overlapping those of Müller's cells and G1 and $\Gamma 1$ amacrine cells; and dramatically different E1 and E4 signatures thus exist for the known glutamatergic classes. Classes E2 and E3 perhaps represent further metabolic forms of glutamatergic neurons. To further complicate matters, the GГ1 class displays a glutamine content intermediate to Müller's cells and ganglion cells, centered on roughly $1 \mathrm{~mm}$. Why a high glutamine content would be required by a presumably inhibitory neuron which has no measurable glutamate content is a mystery. Glutamine levels are very low in both $\Gamma 2$ horizontal cells and $\mathbf{E 3}$ horizontal cells, even though the latter have substantial glutamate signals and low aspartate signals as well.

Taurine (Fig. $8 F$ ). There are no measurable taurine signals in any horizontal cells, while most other cells exhibit supramillimolar levels. The highest levels of taurine in the goldfish neural retina are found in Müller's cells, photoreceptors, and some bipolar cells, as in rat retina (Lake and Verdone-Smith, 1989), and can far exceed $10 \mathrm{~mm}$. Amacrine cells and most bipolar cells possess $5-15 \mathrm{~mm}$ taurine levels, with no clear differentiations among them, while the ganglion cell population displays broad taurine signal dispersion consistent with the presence of taurinebased subtypes within the $\mathbf{E} \mathbf{4}$ signature. We have not analyzed any of these subsets yet. As Müller's cells contain no significant glutamate, glycine, or GABA signals and are dominated by taurine signals, we designate their signature as $\mathbf{T 1}$, with the caveat that dopaminergic interplexiform cells are embedded in that signature at present. Clearly the addition of dopamine or tyrosine hydroxylase to our signal set would fully resolve that small class.

\section{The signature matrix (Fig. 10)}

Many of the complex patterns of content across the nine theme classes are more easily resolved by displaying univariate probability density distributions as an array of small multiples. The unique patterns of signals from the DEGQ $\gamma \gamma$ set are arrayed with putative neurotransmitters $\gamma, \mathrm{G}$, and $\mathrm{E}$ on the left half, and the remainder on the right. Any vertical section demonstrates the patterning of a single amino acid across all classes, and any horizontal section represents the quantitative pattern of amino acids for a single class. The E1, E2, E3, and E4 classes can be seen to be differentiated not only in the mean positions of their glutamate, aspartate, glutamine, glycine, and taurine levels, but also in the dispersions of the signals. Class E3 is likely composed of two or three known kinds of horizontal cells, while both E1 and E4 cells are certain to represent from half to over a dozen cell types. While the signature matrix lacks covariance information, it is nevertheless clear that each of the nine classes are largely discriminable in terms of a few unique features with the sole exception of the $\mathbf{E 2}$ versus $\mathbf{G 1}$ discrimination.

\section{Additional amino acid patterns}

We have not yet found that the patterns of signals derived from alanine, arginine, or serine immunoreactivities contribute to the resolution of any cell types beyond known forms, nor do they yet subdivide postreceptoral neurons or glia (Fig. 11B-D). Alanine immunoreactivity is broadly distributed across many amacrine cell types and some are more immunoreactive than others (Fig. $11 B$ ), but the variance within a class seems to be so broad as not to contribute significantly to the divergence. Arginine signals are widely distributed at extremely low levels that we estimate to be between 100 and $400 \mu \mathrm{M}$ in most cells, are largely excluded from horizontal cell axon terminals but not somas, and seem slightly enriched in rod nuclei (Fig. 11C). While we expected to observe increased arginine levels in neurons suspected to contain nitric oxide synthase, there seems to be no particular arginine pattern one may associate with such functions in goldfish retina, except for horizontal cell somatic content (see also Licpe et al., 1993). The pattern does not contribute to cell classitication. The rod enrichment could be either an artifact of unique arginine-rich histones in rods or a true nuclear trapping of arginine. At present we cannot resolve these suppositions. Finally, serine has been posited as the immediate precursor to glycine based on brain (Daly and Aprison, 1974) and retinal biochemistry (Dasgupta and Narayanaswami, 1982), and we presumed that, like elevated glutamate levels in GABAergic neurons, we might observe a concordance between enriched serine signals and G+ cells. However, no cell-specific serine enrichment is evident in the goldfish retina.

\section{Discussion}

Amino acid signatures account for virtually all cellular space in the goldfish retina and, but for dopaminergic interplexiform cells, each type of neuron in the goldfish retina contains high levels of glutamate, GABA, or glycine

This is not a trivial demonstration since some analyses of mammalian retinal neurons propose up to $30 \%$ of amacrine cells as neither G $\Lambda \mathrm{B} \Lambda$ ergic nor glycinergic (Koontz et al., 1993). Photoreceptors, bipolar cells, and ganglion cells in the goldfish retina are members of glutamate-rich signature classes, and all amacrine cell types, regardless of whether they additionally contain acetylcholine, neuropeptides, or monoamines, belong to GABAergic or glycinergic signature classes. There are five types of cholinergic amacrine cells (Marc et al., 1993) and two types of serotonin-accumulating amacrine cells in the goldfish retina (Marc et al., 1988; Ball and Tutton, 1990; Marc, 1992). All are GABA immunoreactive and are included in the $\boldsymbol{\Gamma} \mathbf{1}$ cohort. All horizontal cells possess either GABAergic $\mathbf{\Gamma} 2$ or novel E3 signatures. We have discovered (1) novel GГ1 cells, (2) a set of bipolar-like cells that could be a homolog of mammalian gly-

Figure 10. The comprehensive $\gamma$ GEDQ $\tau$ signature matrix for all retinal cell classes. Each probability density distribution is amplitude normalized to facilitate concentration comparisons; the abscissa scales range from -1 to $1 \log \mathrm{mm}(0.1-10 \mathrm{~mm})$, with the lower half of each shaded to denote submillimolar levels. Signatures with means below $0.1 \mathrm{~mm}$ are considered background signals and not displayed on the composite. 

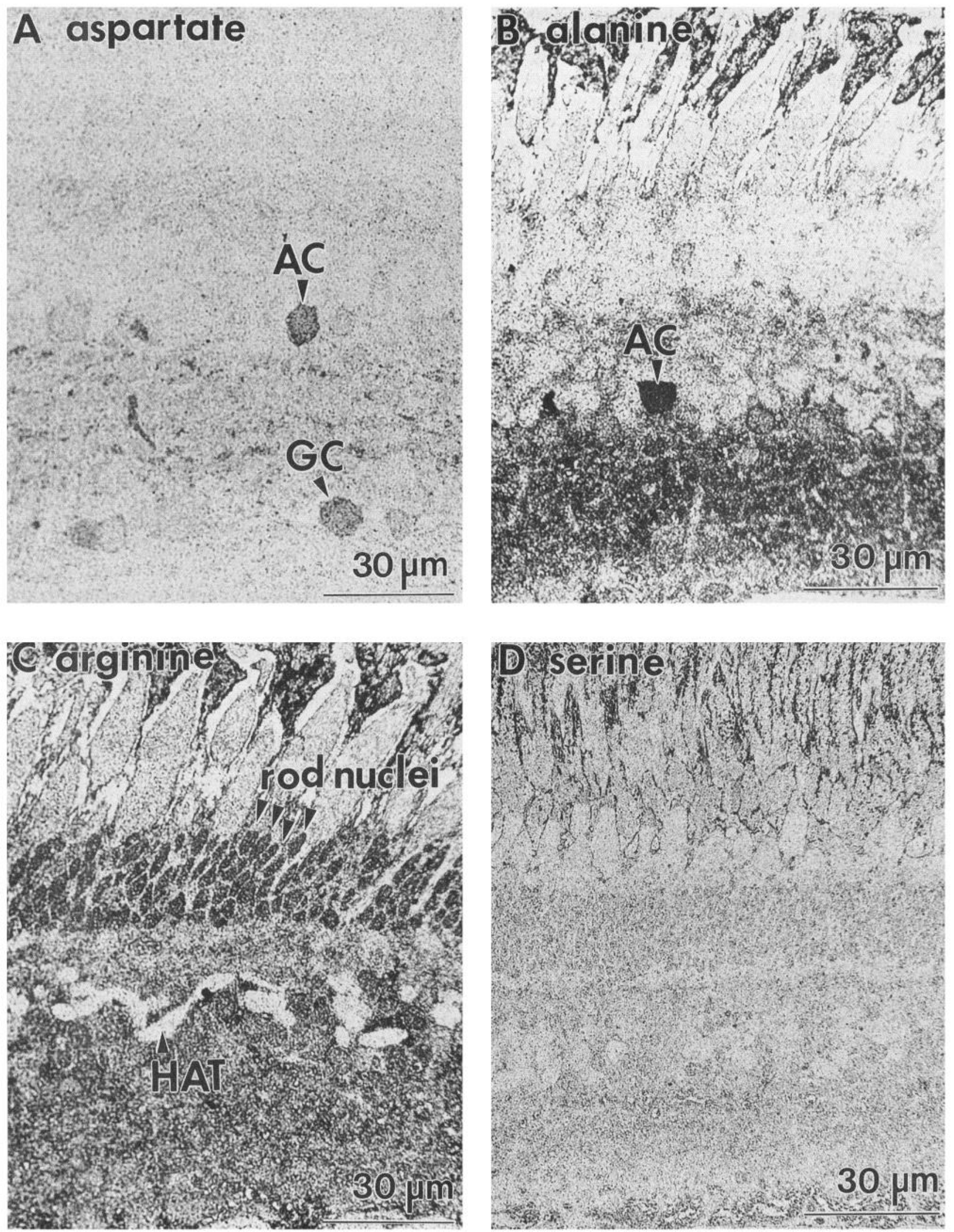

Figure 11. Characteristic signal patterns for L-aspartate, L-alanine, L-arginine, and L-serine. A, L-aspartate immunoreactivity (anti-D IgG 1:2000) $B$, L-alanine (anti-A IgG 1:1000). C, L-arginine (anti-R IgG 1:500). D, L-serine (anti-S IgG 1:200). 
cine-rich cone bipolar cells, and (3) a set of aspartate-enriched I1 amacrine cells.

Some horizontal cells may use glutamate as a neurotransmitter

The neurochemical classification of goldfish horizontal cells has been elusive, but nonmammalian horizontal cells come in two varieties: GABA rich and glutamate rich (Sherry and Ulshafer, 1992; Kalloniatis and Fletcher, 1993). Similarly, every goldfish horizontal cell is assignable to either class $\Gamma 2$ or $\mathbf{E 3}$. The spectrally monophasic $\mathrm{H} 1$ horizontal cells must be class $\Gamma 2$ cells (Marc et al., 1978; Yazulla, 1986). Rod horizontal cells form the innermost layer of horizontal cell somas (Stell, 1967) and possess neither ${ }^{3} \mathrm{H}$-GABA uptake (Marc et al., 1978), nor GAD (Lam et al., 1979; Yazulla, 1986) or GABA immunoreactivity, but are class E3 structures. Rod horizontal cells are thought to lack axon terminal expansions (Stell, 1975) and the presence of E3 axon terminals implies that one or both of the color opponent cone horizontal cells belongs to class E3. Resolution of these assignments will be important as they impact models of horizontal cell color coding (Stell and Lightfoot, 1975). We have no evidence that goldfish $\mathbf{E 3}$ cells can release glutamate, but some avian horizontal cells accumulate ${ }^{3} \mathrm{H}$-D-aspartate (Ehinger, 1981), presumably through a transporter. GABAergic horizontal cells are thought to exert most of their neurochemical effects via transport-mediated efflux (Schwartz, 1982, 1987; Yazulla and Kleinschmidt, 1983; Ayoub and Lam, 1984; Kamermans and Werblin, 1992), and such efflux is a possible mechanism for E3 cells. Some horizontal cells form conventional synapses onto bipolar cclls (Sakai and Naka, 1986; Marshak and Dowling, 1987) and conventional glutamatergic synaptic transmission is also plausible. In any case, a direct sign-conserving pathway from rod horizontal cells to rod-dominated $\mathrm{ON}$-center bipolar cells could generate an appropriate hyperpolarizing surround. Transmission from photoreceptors to ON-center Mb bipolar cells is apparently mediated by an APB-sensitive glutamate receptor, but these cells also possess an additional APB-insensitive glutamate-activated conductance (Nawy and Copenhagen, 1987). Hughes et al. (1992) reported a strong GluR2 AMPA/kainate receptor mRNA signal in rod bipolar cells of rat, though those cells are driven through APB receptors. Further, after APB blockade of photoreceptor (and hence feedback) inputs to tiger salamander ON-center bipolar cells, current injection into horizontal cells can evoke modest sign-conserving responses of proper surround polarity in bipolar cells (Yang and Wu, 1991). These diverse circumstantial data are intriguing but perhaps of dubious relevance to the goldfish, and the hypothesis that some horizontal cells use glutamate remains speculation.

\section{Aspartatergic transmission in the goldfish is unlikely}

Enhanced aspartate immunoreactivity is not restricted to amacrine cells and can be found in bipolar, horizontal, and/or ganglion cells in turtle, lizard, and chicken (Yaqub and Eldred, 1991; Sherry and Ulshafer, 1992; Kalloniatis and Fletcher, 1993), though absolute aspartate levels are not known. If aspartate were to function as a goldfish retinal neurotransmitter (perhaps at NMDA receptors), it would likely have to be co-released from certain GABAergic amacrine cells, as only those cells contain significant aspartate levels. However, L-aspartate does not load any known synaptic vesicle systems (Kish and Ueda, 1989; Tabb and Ueda, 1991) and so would conceivably have to be released by a transporter. We believe the evidence does not support aspartate as a potential retinal neurotransmitter. Circum- stances may be different in the CNS (e.g., climbing fibers in cerebellum; Zhang et al., 1990).

\section{Taurine is most likely an osmolyte in goldfish retina}

Our results reveal that every cell in the goldfish retina (except horizontal cells) contains more taurine than any other amino acid, similar to but not identical with the mammalian pattern. This distribution is not consistent with a role as a conventional neurotransmitter. Taurine evokes strychnine-sensitive conductance increases in mudpuppy bipolar cells and ganglion cells (Cunningham and Miller, 1980) indistinguishable from those evoked by glycine. However, $\mathrm{K}^{+}$-evoked retinal taurine release is largely $\mathrm{Ca}^{2+}$ independent and correlates with volume regulation events (Domínguez et al., 1989). There is no known vesicular transport system for taurine. Though photoreceptor cells contain at least 10-fold more taurine than glutamate, photoreceptor to second-order neuron transmission is not impacted by taurine application (Cunningham and Miller, 1980). Taurine is not known as a key metabolite in neuronal metabolism, so how can one account for the high levels and global distribution of taurine? One plausible interpretation is that taurine has another, more pervasive function such as osmoregulation (Huxtable and Sebring, 1986). In fish, regulation of cerebrospinal fluid/blood tonicity is mediated in part by taurine-dominated amino acid fluxes (Forster et al., 1978), and taurine fluxes also correlate with osmotic challenge in mammalian brain (Schousboe et al., 1992). The extracellular volume in the subretinal space varies with activity (Huang and Karwoski, 1992), implying natural compensatory osmotic responses. On balance, the hypothesis that taurine is involved in retinal osmoregulation deserves careful exploration.

Multiple forms of metabolic profiles may be associated with a single nominal neurotrarismiller calegory

In the goldfish, at least two different metabolic profiles exist for each glutamatergic and GABAergic cell system. Class $\mathbf{\Gamma 1}$ and $\Gamma \mathbf{2}$ cells are GABAergic by classical criteria (e.g., Yazulla, 1986; Marc, 1992) but differ in GABA, aspartate, glutamine, and taurine levels. Differentiation of GABAergic neurons based on taurine content has previously been noted in cerebellum (Ottersen et al., 1988) and cortex (Kritzer et al., 1992), but the difference in taurine signals is not explicable in terms of any obvious metabolic model (see review by Lombardini, 1991). Photoreceptors, bipolar cells, and most ganglion cells are generally considered to be glutamatergic neurons (Ehinger et al., 1988; Massey, 1990; Marc et al., 1990), but the signatures of class $\mathbf{E} 4$ ganglion cells differ from the E1 bipolar cell/photoreceptor class profile with approximately four times the glutamine, twice the aspartate, and less than one-fifth the taurine. These differences may be constitutive, due to variations in enzyme expression, or derivative, reflecting size-, shape-, location-, or activity-associated differences in metabolite sources and sinks. Two features distinguish the presumed release modes of photoreceptor/bipolar and ganglion cells: (1) the former are slow potential systems, whereas ganglion cells obligatorily use action potentials; (2) photoreceptor/bipolar cells are small cells and the release sites of goldfish retinal ganglion cells are in the tectum and thalamus. The synthesis of glutamate is largely intramitochondrial and, as a cell's mitochondrial cohort is presumably homogeneous, the somas of ganglion cells likely make glutamate in the same way as their terminals. It is intriguing that the glutamate:glutamine ratio of presumed glutamatergic mossy fiber systems is $4.6: 1$ as calcu- 
lated from calibrated immunogold binding corrected for fixation efficiency (Ottersen et al., 1992) and 5:1 for goldfish retinal ganglion cells as estimated by our scaling and compartmentalization scheme, since both are excitatory projection neurons. That metabolic differences exist for neurons with different modes of action is, perhaps, not very surprising. Clearly, many questions remain: Are the differences static? Are they intrinsic and genetically determined or conditioned by the environment in which the neurons are embedded? Do such metabolic differences predispose one or another class to failure in pathophysiological states? In this sense, cone photoreceptors provide a provocative model because they can continue to function under conditions where they appear to contain very little free glutamate (Fig. 2A).

\section{Signatures can serve as quantitative measures of cell state}

We have taken care to ensure that the signatures derived are stable by using standardized preparations. Nevertheless, neuronal or glial signatures can change in response to both benign treatments, such as state of light adaptation (Fig. 2), and nonphysiological interventions, such as induced depolarization (hippocampus, Gundersen et al., 1991; R. E. Marc, R. F. Murry, S. F. Basinger, unpublished observations) or experimental retinal detachment (Marc et al., 1995), where massive changes in cellular amino acid signatures occur. In general, pattern recognition offers a more stable, defined means of characterizing cell systems than simple observation of immunocytochemical staining intensities.

\section{Appendix}

This appendix provides details of our methods and some explanation of underlying theory. We also specify basic imaging references and products we have found to be particularly useful.

\section{Image calibration and signal interpretation}

Images of immunoreactivity were captured into a MegaVision 1024XM (MegaVision Inc., Santa Barbara, CA) imaging system with a PULNiX TM-7 CCD (PULNiX America Inc., Sunnyvale, CA) camera mounted on a conventional light microscope using protocols similar to those described in Marc et al. (1990), and stored as 512 pixel $\times 512$ line image frames. Images were captured under constant flux $550 \mathrm{~nm}$ (10 nm bandpass) light using fixed camera gain and $\gamma$, yielding a log-linear pixel value (PV) scale over the usable irradiance. Images of dot assays and/or sectioned gelatin-glutaraldehyde-amino acid microstandards captured under the same conditions generated look-up tables for estimates of intracellular concentration scaling. PV scales linearly with $\log$ concentration in our system over a $2 \log$ unit range. It is not possible to directly measure intracellular concentrations by comparing standards to tissues as we do not know the true density of intracellular immobile matrix sites; that is, the terminal $\mathrm{NH}_{2}$ groups on proteins, RNA, DNA, etc., to which the mobile free amino acids are cross-linked. However, making the reasonable assumptions that immobile matrix densities are high and that amino acid losses on fixation are isotropic across cell types, the scaling of signals in cells will reflect the compartmentalization of a given amino acid. If fixation losses are anisotropic (something provable only upon demonstration), then specific corrections can later be applied to our calculated values. Similarly, once true immobile matrix densities are known, the efficiencies of cross-linking in mixed amino acid regimes can be determined and used to further refine our data, if necessary.
Intracellular concentrations were estimated as described in detail in Marc et al. (1990).

\section{Image registration}

The power of the single-section postembedding technique derives from strong signal segregation (only one probe is applied per section) and the possibility of using multiple probes: we have used up to 12 in a single experiment. Serial sections must be accurately registered to exploit this power and thinner sections yield better registrations. IgG binding in the postembedding procedure is almost entirely a surface phenomenon, independent of section thickness (Bendayan, 1984; Marc et al., 1990; Beier, 1992), and we obtain identical immunoreactivities for our entire antigen panel over the range of $40-1000 \mathrm{~nm}$ section thickness. While $40 \mathrm{~nm}$ sections are too thin for most electron microscopic applications due to poor mass thickness (Meek, 1976), they are superb for image registration since a series of 12 antigens can be tested within a span of less than $500 \mathrm{~nm}$. Such ultrathin sections are too fragile for analysis of large horizontal sections ( $>2 \mathrm{~mm}$ on a side), and we find that $200-250 \mathrm{~nm}$ sections are adequate for routine work. The basic concepts of digital image registration are described by Wolberg (1990) and involve identifying common points known as control points across a set of images. We have previously outlined our basic procedures (Marc et al., 1990). One image is selected as a master and the translations, rotations, scalings, and shears required to align all points on any image to the master image are calculated by spatial interpolation. Most registrations involve first-order polynomial or simple affine transformations: linear coordinate transformations plus translation terms. On occasion, however, local distortions such as a stretched section will preclude successful alignment with a first-order model, and a higher-order polynomial solution must be estimated. Such higher-order polynomials require that a reasonable number of control points be distributed across the image, and since it is not possible to predict when or where such fits will be needed, our standard method involved selecting 2550 control points spread over the entire image. Series of sections were aligned pairwise by conventional image registration methods (EASI/PACE software from PCI Remote Sensing, Arlington, VA) using common landmarks such as Müller's cell borders, blood vessels, bipolar cell terminals, nuclei, soma boundaries, photoreceptors, etc., as control points. Most images were registered with better than $250 \mathrm{~nm}$ RMS (root mean square) error and many were below $200 \mathrm{~nm}$ RMS error. Small structures less than $500 \mathrm{~nm}$ in extent can be aligned for only a few serial sections, primarily due to the Rayleigh limit, but we are generally not interested in classifying neuropil in this work. Even the smallest cone bipolar cells were easily aligned by standard georeferencing algorithms. The border of every cell will grow or shrink in fairly predictable ways through a series of sections, forming a small kerf of registration failures that may be partially suppressed by low-pass filtering the images. Low-pass filtering is also desirable to suppress intracellular variations arising from intracellular inclusions such as mitochondria, nuclei, endosomes, etc., which are routinely visible with light microscopic ultrathin section immunocytochemistry. A second way of suppressing the kerf occurs in the application of pattern recognition techniques (see below) wherein most residual kerf areas are detected and excluded from theme classes.

\section{Image visualization}

Amino acid signals in immunoreacted sections are optically absorbing and scale inversely with pixel value (density scaling: PV 


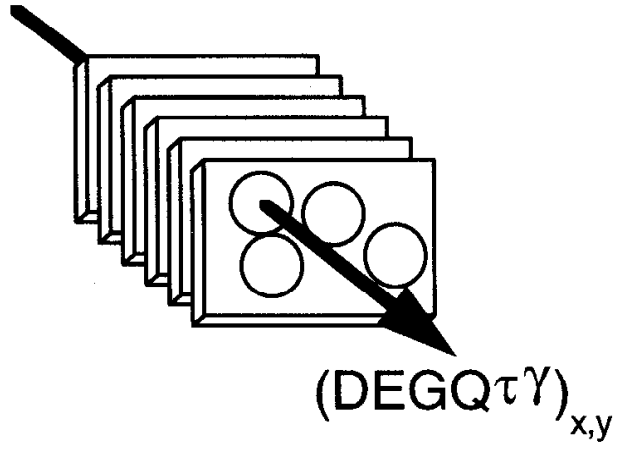

Figure 12. A stack of registered sections serially probed for aspartate $(D)$, glutamate $(E)$, glycine $(G)$, glutamine $(Q)$, GABA $(\gamma)$, and taurine $(\tau)$. Fvery common point in the stack is characterized by a six-dimensional descriptor: $P(x, y)=\mathrm{DEGQ} \tau \gamma(x, y)$.

$255 \rightarrow 0$ for eight-bit systems). However, the conventional way to examine correlated signals involves $r g b$ mapping, using the brightness signals from one amino acid to drive one color gun. Images were therefore inverted with a logical NOT operation so that immunoreactivity scaled with increasing brightness (brightness scaling: PV $0 \rightarrow 255$ ). Thus any triplet of amino acids can be simultaneously viewed with $r g b$ mapping. This serves as a useful survey tool, but cannot be used for quantitative analysis. The correct approach is multidimensional pattern recognition.

\section{Pattern recognition}

Pattern recognition theory is similar to univariate signal detection theory in engineering and psychology, but is $N$ dimensional and was developed, in large part, for multispectral analysis of planetary imaging data. A set of serial sections probed with amino acids (Fig. 12) is similar to a series of planetary photographs taken through different spectral filters. After imaging and registration, common points on each image will each contribute one value to a list of values representing planetary spectral reflectance or, in the neuroscientist's case, amino acid contents.

Viewing the data as side-by-side images or as digital color image pairs or triplets (amino acid $r g b$ mapping) aids in finding the most obvious relations. However, visual examination is not a statistical assessment, nor can one see variance. A series of six images produces 15 unique doublets and 20 triplets, while a 10-channel image yields 120 triplets. In general, $N$ images generate $[N !] /[(R !)(N-R) !]$ sets taken $R$ at a time. Already visually unmanageable, the problem is exacerbated by the task of classifying several hundred cells into an unknown number of meaningful groups. One solution to this classical $N$-dimensional clustering problem is the $K$-means algorithm wherein $N$-dimensional means and variances for classes are obtained by calculating hypersurface decision boundaries (Duda and Hart, 1973; Tou and Gonzales, 1974; see Dasarathy, 1991, for a collection of critical papers in pattern recognition theory). A two-dimensional plot of simplified glutamate and aspartate signals typical of goldfish bipolar and amacrine cells may be used as an example. Starting from some initial means, the $K$-means algorithm calculates an initial decision boundary, assigns all points on one side to a group, and iteratively calculates new means and boundaries until it converges on clusterings that do not change significantly with subsequent iterations (Fig. 13). All points on one side of the decision boundary constitute a theme class. This is merely the two-dimensional, two-class case, and while interpreting data sets of higher dimensionality is visually difficult or impossible, computing classes and decision boundaries is not. Theme classes represent clusters of highly correlated signals in the $N$-space for which decision boundaries can be defined, and each set of $N$ means and variances characterizing a single theme class is the formal class signature. In practice, the initial means for the iterations were taken from sampled image values, allowed to converge on more theme classes than actually expected, and any extra inappropriate classes merged (e.g., differentiation of the nucleus from cytoplasm in the same cell). ${ }^{\prime}$ These tactics ensured capturing all the functional classes. All of the software for performing pattern recognition was obtained from PCI Remote Sensing (Arlington, VA).

Clustering data by minimization techniques does not ensure

The true origins of cytosolic versus nuclear variations in immunoreactivity are unclear but are not likely due to differences in levels of fixed cytosolic and nuclear amino acids. This is unequivocally clear from electron microscopic autoradiographic data: both access and fixation efticiencies of amino acids are effectively identical for both compartments (cf. Muller and Marc, 1990). In our view, the variation is most likely caused by the fact that many of the primary immobile matrix sites in the nucleus are on polynucleotides and yield final conjugates such as adenine-glutaraldehyde-amino acid for which the affinities of IgGs generated against lysine-glutaraldehyde-amino acid haptens are significantly lower

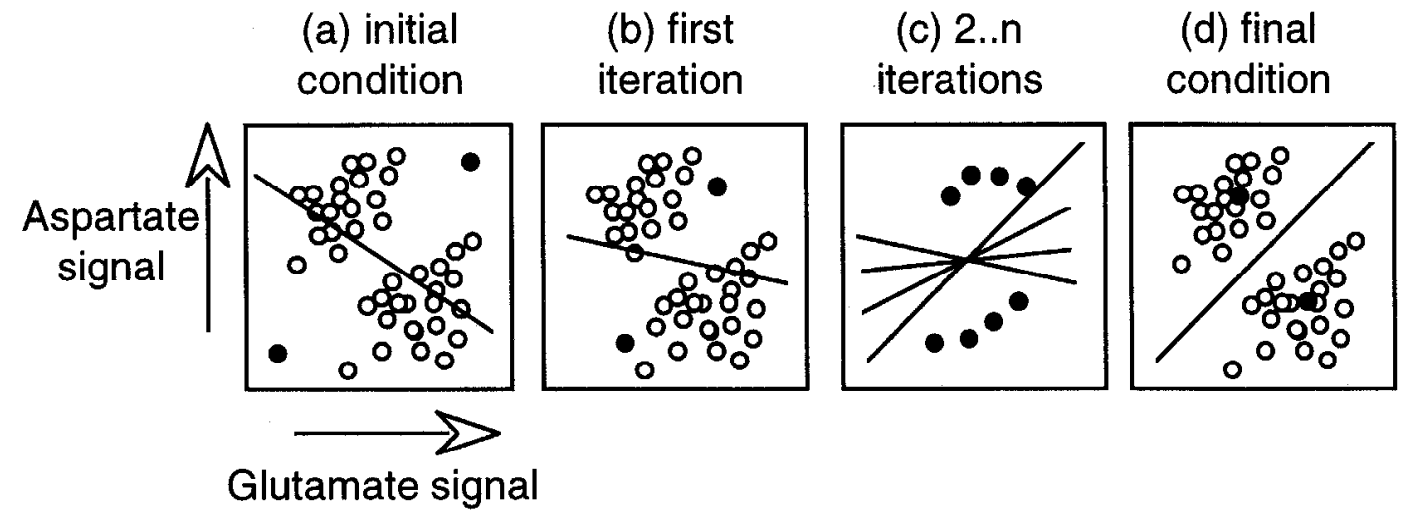

Figure 13. Four panels illustrating the general tactics of an iterative clustering algorithm. $\bigcirc$, idealized glutamate and aspartate values representative of samples from E1 bipolar cells and $\Gamma 1$ amacrine cells. $a$, Two arbitrary initial means are chosen () and an initial decision boundary separating them is calculated (line) $b$, A new mean is calculated for each side from all the points falling on a given side of the decision boundary, and a new boundary computed. $c$, The process repeats until it no longer produces shifts in the bivariate means and converges upon the final class means and decision boundaries $(d)$. 


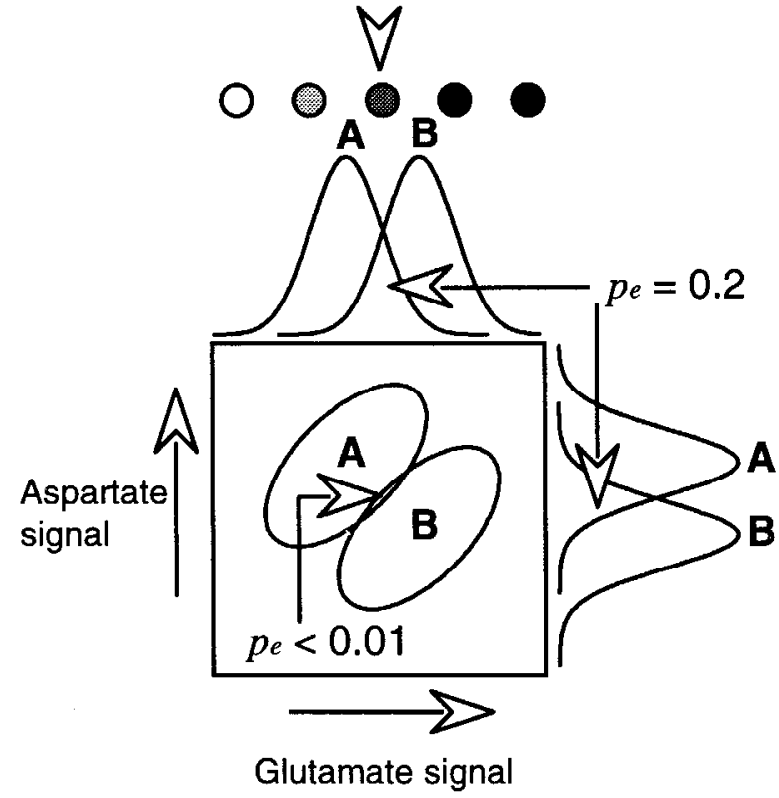

Figure 14. Summary bivariate distributions of idealized amacrine $(\Lambda)$ and bipolar cell $(B)$ glutamate and aspartate signals. The ellipses are the $2 \mathrm{SD}$ borders of the bivariate data sets and the unimodal profiles represent the marginal univariate distributions for the glutamate ( $t o p$ ) and aspartate signals (right side) of each cell class. The integrated $p_{e}$ values for each of the overlap zones are indicated by arrows. The five spots at top represent idealized immunoreactivities associated with cells having low to high glutamate signals, and a cell possessing an intermediate signal common to both distributions is indicated (arrowhead).

that a local minimum (a possible theme class) is a valid statis tical entity, but derived classes can be tested for their statistical separabilities by a probability of error $\left(p_{e}^{\prime}\right)$ assessment. This is typically done by calculating the $N$-dimensional divergences of the data and modeling $p_{e}$ for various a priori probability density functions. We employed transformed divergence $\left(D^{T}\right)$ as a routine statistic for estimating the degree of pairwise theme class segregation (Swain and Davis, 1978). Use of $D^{\top}$ is conditioned by the assumption that the underlying univariate theme class signal distributions are largely normal or may be decomposed into single normal distributions. We verified this for almost all signals in all classes by extracting the univariate signal histogram for each amino acid in each theme class and modeling the data with the minimum number of Gaussians required to achieve a good least squares fit (minimum $r>0.95$; Jandel PEAKFIT, Jandel Scientific, San Rafael, CA). All histograms were strongly dominated by a single Gaussian or decomposable into 2 or 3 Gaussians. $D^{T}$ is a robust statistic immune to even large deviations from normality. Moreover, it is an additive statistic and increasing the number of data channels (amino acids) does not decrease separability even if the new channel does not contribute further discrimination of a pair of theme classes. The relationship between $D^{T}$ and direct calculation of probability of error $\left(p_{\mathrm{e}}\right)$ in classification is complicated by high dimensionality of the data and differing a priori probabilities (i.e., the relative densities of the theme class or cell types in the data set). For practical purposes, the conventional assumption of roughly equal a priori probabilities across all theme classes is fairly reasonable for our data, and $D^{T}$ ranges from 0 (no separability and $p_{e}-1$ ) to 2 (full separability, $p_{e}=0$ ). The primary consequence of deviation from equal a priori probabilities is a failure to recognize a potentially valid class as statistically separable, and we have only one such incident in our data set. The standard cutoff of significance in $D^{T}$ is 1.9 , corresponding to $p_{e}<0.01$. All but one of the theme classes we report here have $D^{r} \geq 1.9$. The importance of $p_{e}$ is illustrated in Figure 14, which displays bivariate ellipses representing the $2 \mathrm{SD}$ borders for each class in the glutamate aspartate clusters of Figure 13 and compares them with the univariate marginal distributions. Three important concepts are illustrated. (1) Pattern recognition uses $N$-dimensional covariance. Though the bivariate distributions have little overlap and a low $p_{e}$, the univariate data overlap extensively with high $p_{e}$ terms since univariate data cannot encode covariance. While many amacrine cells have as much glutamate as bipolar cells, the bivariate distribution reveals that such cells usually have much more aspartate in them. Pattern recognition thus detects covariance: hidden biology that visual examination alone can neither extract nor document. (2) The classification error $p_{e}$ is a more aggressive initial measure than $P$ values from classical hypothesis testing. The univariate distributions represent significantly different populations in the traditional sense, and the null hypothesis $\mathrm{H}_{0}$ may be rejected at the $P<0.01$ level. If one were required to name the group from which a given sample arose based on the strength of one type of signal alone, however, the $p_{e}$ would be unacceptably high. For example, the gray cell indicated at the top of Figure 14 would be misclassified $50 \%$ of the time and the integrated error for the entire range of data would be 0.2 , over an order of magnitude higher than the bivariate $p_{e^{*}}$. Such errors are not trivial and are abundant in the literature of immunocytochemistry. Alternatively, data derived from dual probe measurements clustered by pattern recognition algorithms would permit nearly error-free assignations. The
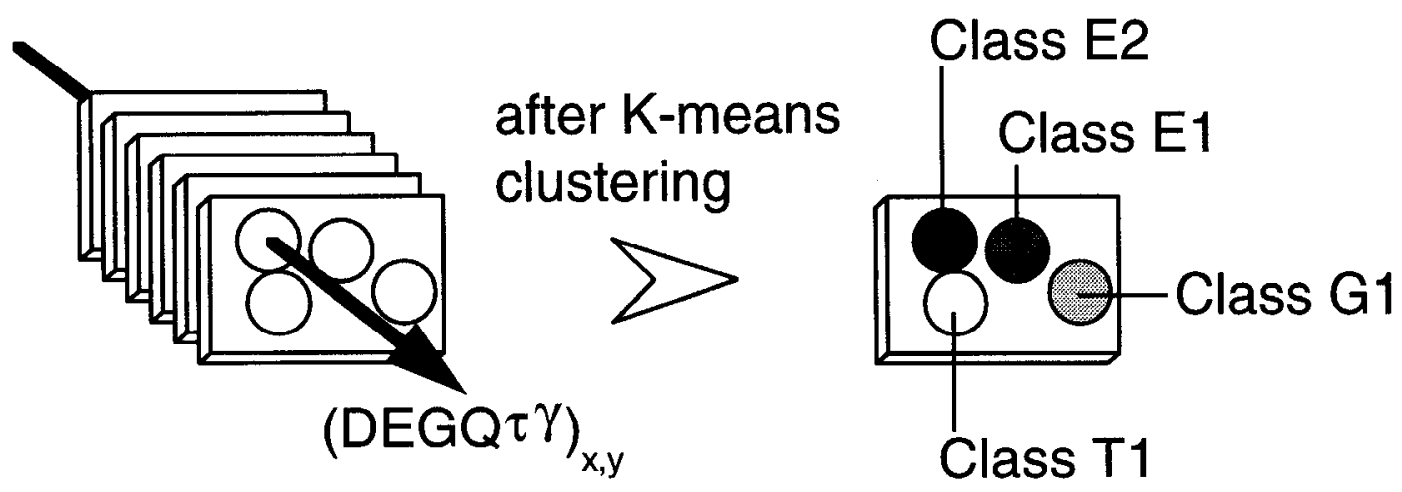

Figure 15. A theme map is constructed from the six-dimensional data set, and each theme class derived in the analysis is coded on the map. Each code then constitutes a binary mask that can be used to explore the signal contents of that class alone. 
reader should be sure to distinguish between $p_{e}$ as a measure of statistical separability in pattern recognition and $P$ as the conventional measure of statistical significance in hypothesis testing. (3) Pattern recognition is essentially independent of signal scaling. Derivation of this property is beyond the scope of this appendix but it should be geometrically obvious by examining the bivariate space: stretching or compressing it does not alter the number of classes. While some may disagree with our absolute values for amino acid levels, the classifications extracted by pattern recognition are nonetheless stable and valid. Even very nonlinear scalings are tolerable as long as they are smoothly continuous and monotonic.

A prime goal of pattern recognition is to interpret the original image and this is done by generating a theme map. Each $\mathrm{N}$-dimensional signature class is labeled with a unique color, and in this sense theme maps are similar to political maps. As the signatures themselves are complex, meaningful names to track theme classes are essential. There may have been four statistically different cell types in our original stack of sections (Fig. 12) and they may now be represented in a theme map (Fig. 15) that reveals the physical compartmentalizations of the formal signature classes: E1, E2, G1, and T1 (see Materials and Methods, Nomenclature). The letters denote the distinctive amino acid in a cell population using conventional biochemical notation and the numeric or alphanumeric suffixes indicate statistical subtypes of that general class. For example, class $\mathbf{E}$ represents glutamaterich neurons and classes E1-4 are associated with different biochemical groups of glutamate-rich cells. This is rather like assigning class $\mathbf{W}$ to represent bodies of water and subclasses W1-4 as oceans, rivers, lakes, and marshes.

Results of $K$-means classifications were visualized in four ways. (1) Theme maps were constructed by color coding every pixel in the original image according to theme class, allowing one to see how well classifications of structural space based on biochemical signals alone corresponded to real cells. (2) Bivariate probability density distributions allowed examination of both separations and covariances of theme classes for pairs of amino acids. Raw bivariate scatterplots of $N$-dimensional data mapped onto a two space were augmented by viewing the $\sin$ gle-class ellipses for each theme class: the $2 \mathrm{SD}$ borders of the bivariate Gaussians underlying each theme class. (3) Univariate probability density distributions for each theme class were extracted from original $N$-space data frames by using each theme class as a binary mask (see Marc et al., 1990; univariate histogram extraction was perfunned under IMAGEPRo PLus for Windows, Media Cybernetics, Silver Spring, MD). This reveals the extent to which the strengths of various amino acid signals overlap across cell classes, but cannot encode covariance. (4) A signature matrix was constructed as a small multiple plot (Tufte, 1983) of all the aligned univariate probability density distributions for each amino acid versus all theme classes. This is a comprehensive view of signature types.

\section{References}

Altschuler RA, Neises GR, Harmison GG, Wenthold RJ, Fex J (1981) Immunocytochemical localization of aspartate aminotransferase immunoreactivity in cochlear nucleus of the guinea pig. Proc Natl Acad Sci USA 78:6553-6557.

Altschuler RA, Mosinger JL, Harmison GG, Parakkal MH, Wenthold RJ (1982) Aspartate aminotransferase-like immunoreactivity as a marker for aspartate/glutamate in guinea pig photoreceptors. Nature 298:657-659.
Attwell D, Mobbs P (1994) Neurotransmitter transporters. Curr Opin Neurobiol 4:353-359.

Ayoub GS, Lam DMK (1984) The release of $\gamma$-aminobutyric acid from horizontal cells of the goldfish (Carassius auratus) retina. J Physiol (Lond) 355:191-214.

Ball AK, Tutton DA (1990) Contacts between S1 amacrine cells and "I1" interplexiform cells in the goldfish retina. Invest Ophthalmol Vis Sci [Suppl] 33:1405.

Beier K (1992) Light microscopic morphometric analysis of peroxisomes by automated image analysis: advantages of immunostaining over the alkaline DAB method. J Histochem Cytochem 40:115-121.

Bendayan M (1984) Protein-A gold electron microscopic immunocytochemistry: methods, applications and limitations. J Electron $\mathrm{Mi}$ crosc Tech 1:243-253.

Brew H, Attwell D (1987) Electrogenic glutamate uptake is a major current carrier in the membrane of axolotl retinal glial cells. Nature 327:707-709.

Cohen E, Sterling P (1986) Accumulation of 3H-glycine by cone bipolar neurons in the cat retina. J Comp Neurol 250:1-7.

Cunningham RA, Miller RF (1980) Electrophysiological analysis of taurine and glycine actions in neuron of the mudpuppy retina. I. Intracellular recordings. Brain Res 197:123-138.

Daly EC, MH Aprison (1974) Distribution of serine hydroxymethyltransferase and glycine transaminase in several areas of the central nervous system. J Neurochem 22:877-885.

Dasarathy BV (1991) Nearest neighbor (NN) norms: NN pattern classification techniques. Los Alamitos, CA: IFFF, Computer Society.

Dasgupta P, Narayanaswami A (1982) Serine hydroxytransmethylase activity in vertebrate retina. $J$ Neurochem $39: 743-746$.

Domínguez L, Montenegro J, Pasantes-Morales H (1989) A volumedependent, chloride sensitive component of taurine release stimulated by potassium from retina. $\mathrm{J}$ Neurosci Res 22:356-361.

Duda RO, Hart PE (1973) Pattern classification and scene analysis. New York: Wiley.

Ehinger B (1981) $\left[{ }^{3} \mathrm{H}\right]$-D-aspartate accumulation in the retina of the pigeon guinea pig and rabbit. Exp Eye Res 33:381-391.

Ehinger B, Ottersen OP, Storm-Mathisen J, Dowling JE (1988) Bipolar cells in the turtle retina are strongly immunoreactive for glutamate. Proc Natl Acad Sci USA 85:8321-8325.

Forster RP, Hannafin JA, Goldstein L (1978) Osmoregulatory role of amino acid in brain of the elasmobranch, Raja erinacea. Comp Biochem Physiol [A] 60:25-30.

Gundersen V, Ottersen OP, Storm-Mathisen J (1991) Aspartate- and glutannate-like innmunoreactivities in rat hippocampal slices: depolarization-induced redistribution and effects of precursors. Eur J Neurosci 3:1281-1299.

Hamberger AC, Chiang $\mathrm{CH}$, Nylen ES, Scheff SW, Cotman CW (1979a) Glutamate as a CNS transmitter. I. Evaluation of glucose and glutamine as precursors for the synthesis of preferentially released glutamate. Brain Res 168:513-530.

Hamberger AC, Chiang CH, Sandoval E, Cotman CW (1979b) Glutamate as a CNS transmitter. II. Regulation of synthesis in the releasable pool. Brain Res 168:513-530.

Hendrickson AE, Koontz MA, Pourcho RG, Sarthy PV, Goebel DJ (1988) Localization of glycine-containing neurons in the Macaca monkey retina J Comp Neurol 273:473-487.

Hökfelt T, Millhorn D, Seroogy K, Ceccatelli S, Lindh B, Meister B, Melander M, Schalling M, Bartfai T, Terenius L (1987) Coexistence of peptides with classical neurotransmitters. Experientia 43:768-780.

Huang B, Karwoski C (1992) Light-evoked expansion of the subretinal space volume in the retina of the frog. J Neurosci 12:4243-4252.

Hughes TE, Hermans-Borgmeyer I, Heinemann S (1992) Differential expression of glutamate receptor genes (GluR 1-5) in the rat retina. Vis Neurosci 8:49-55.

Huxtable RJ, Sebring LA (1986) Towards a unifying theory for the actions of taurine. Trends Pharmacol Sci 7:481-485.

Ishida AT, Stell WK, Lightfoot DO (1980) Rod and cone inputs to bipolar cells in goldfish retina. J Comp Neurol 191:315.

Kalloniatis M, Fletcher E (1993) Immunocytochemical localization of the amino acid neurotransmitters in the chicken retina. J Comp Neurol 336:174-193.

Kalloniatis M, Tomisch G, Marc RE (1994) Neurochemical signatures revealed by glutamine labeling in the chicken retina. Vis Neurosci 11:793-804.

Kamermans M, Werblin F (1992) GABA-mediated positive autofeed- 
back loop controls horizontal cell kinetics in tiger salamander retina. J Neurosci 12:2451-2463.

Kish PE, Ueda T (1989) Glutamate accumulation into synaptic vesicles. Methods Enzymol 174:9-25.

Kolb H (1982) The morphology of the bipolar cells, amacrine cells, and ganglion cells in the retina of the turtle Pseudemys scripta elegans.. Philos Trans R Soc Lond [Biol] 298:355-393.

Kolb H, Nelson R, Mariani A (1981) Amacrine cells, bipolar cells, and ganglion cells of the cat retina. A Golgi study. Vision Res 21:10811114.

Koontz MA, Hendrickson LE, Brace ST, Hendrickson AE (1993) Immunocytochemical localization of GABA and glycine in amacrine and displaced amacrine cells of macaque monkey retina. Vision Res 18:2617-2628.

Kritzer MF, Cowey A, Ottersen OP, Streit P, Somogyi P (1992) Immunoreactivity for taurine characterizes subsets of glia, GABAergic and non-GABAergic neurons in the neo- and archicortex of the rat, cat and rhesus monkey: comparison with immunoreactive for homocysteic acid. Eur J Neurosci 4:251-270.

Kvamme E, Torgner IAA, Svenneby G (1985) Glutaminase from mammalian tissues. Methods Enzymol 113:241-256.

Lake N, Verdone-Smith C (1989) Immunocytochemical localization of taurine in the mammalian retina. Curr Eye Res 8:163-173.

Lake N, Marshall J, Voaden MJ (1978) Iligh affinity uptake sites for taurine in the retina. Exp Eye Res 27:713-718.

Lam DMK, Su YYT, Swain L, Marc RE, Brandon C, Wu JY (1979) Immunocytochemical localization of glutamic acid decarboxylase in the goldfish retina. Nature 278:565-567.

Lam DMK, Marc RE, Sarthy PV, Chin CA, Su YYT, Brandon C, Wu JY (1980) Retinal organization: neurotransmitters as physiological probes. Neurochemistry 1:183-190.

Lam DMK, Li H-B, Su YYT, Watt CB (1985) The signature hypothesis: co-localizations of neuroactive substances as anatomical probes for neurocircuitry analysis. Vision Res 25:1353-1364.

Liepe B $\Lambda$, Stone C, Copenhagen D (1993) Localization of NADPHdiaphorase positive cells in fish and salamander retinas. Invest Ophthalmol Vis Sci [Suppl] 34:752.

Lombardini JB (1991) Taurine: retinal function. Brain Res Rev 16: $151-169$

Marc RE (1982) Spatial organization of neurochemically classified interneurons in the goldfish retina. I. Local patterns. Vision Res 22 : 589-608.

Marc RE (1985) The role of glycine in retinal circuitry. In: Retinal transmitters and modulators: models for the brain, Vol 1 (Morgan W, ed), pp 119-158. Boca Raton, FL: CRC.

Marc RE (1989a) The anatomy of multiple GABAergic and glycinergic pathways in the inner plexiform layer of the goldfish retina. In: NATO ASI series, Vol H31a, Neurobiology of the inner retina (Weiler R, Osborne NN, eds), pp 53-64. Berlin: Springer.

Marc RE (1989b) The role of glycine in the mammalian retina. In: Progress in retinal research, Vol 8 (Osborne N, Chader G, eds), pp 67-107. London: Pergamon.

Marc RE (1992) The structure of GABAergic circuits in ectotherm retinas. In: GABA in the retina and central visual system (Mize $\mathbf{R}$, Marc RE, Sillito A, eds), pp 61-92. Amsterdam: Elsevier.

Marc RE (1994) Visualizing amino acids in the retina. In: The first great basin symposium on visual science, pp 58-67. Salt Lake City: University of Utah.

Marc RE, Lam DMK (1981a) Glycinergic pathways in the goldfish retina. J Neurosci 1:152-165.

Marc RE, Lam DMK (1981b) Uptake of aspartic and glutamic acid by goldfish photoreceptors. Proc Natl Acad Sci USA 78:7185-7189.

Marc RE, Liu W-LS (1984)Glycine-accumulating neurons in the human retina. J Comp Neurol 232:241-260.

Marc RE, Stell WK, Bok D, Lam DMK(1978) GABAergic pathways in the goldfish retina. J Comp Neurol 182:221-246.

Marc RE, Liu W-LS, Scholz K, Muller JF (1988) Serotonergic pathways in the goldfish retina. J Neuroscience 8:3427-3450.

Marc RE, Liu W-LS, Kalloniatis M, Raiguel S, Van Haesendonck E (1990) Patterns of glutamate immunoreactivity in the goldfish retina. J Neurosci 10:4006-4034.

Marc RE, Li H-B, Kalloniatis M, Arnold J (1993) Cholinergic subsets of GABAergic amacrine cells in the goldfish retina. Invest Ophthalmol Vis Sci [Suppl] 34:1061.

Marc RE, Murry RF, Fisher SK, Lewis GP, Linberg KA (1995) The cellular amino acid signatures of the cat retina: transitions from normal to pathological states following retinal detachment. Invest Ophthalmol Vis Sci [Suppl] 36: in press.

Marshak DW, Dowling JE (1987) Synapses of the cone horizontal cell axons of the goldfish retina. J Comp Neurol 256:430-443.

Martin DL (1987) Regulatory properties of brain glutamate decarboxylase. Cell Mol Neurobiol 7:237-253.

Martin PR, Grünert U (1992) Spatial density and immunoreactivity of bipolar cells in the macaque monkey retina. J Comp Neurol 323:269287.

Massey SC (1990) Cell types using glutamate as a neurotransmitter in the vertebrate retina. In: Progress in retinal research, Vol 9 (Osborne NN, Chader G, eds), pp 399-425. London: Pergamon.

Matute C, Streit P (1986) Monoclonal antibodies demonstrating GABA-like immunoreactivity. Histochemistry 86:147-157.

Meek GA (1976) Practical electron microscopy for biologists. London: Wiley.

Muller JF, Marc RE (1990) GABA-ergic and glycinergic pathways in the inner plexiform layer of the goldfish retina. J Comp Neurol 291: 281-304.

Nawy S, Copenhagen D (1987) Multiple classes of glutamate receptor on depolarizing bipolar cells in the retina. Nature 325:56-58.

Ottersen OP, Madsen S, Storm-Mathisen J, Somogyi P, Scopsi L, Larsson L-I (1988) Immunocytochemical evidence that taurine is colocalized with GABA in the Purkinje cell terminals, but that the stellate cell terminals predominantly contain GABA: a light- and electron microscopic study of the rat cerebellum. Exp Brain Res 72:407-416.

Ottersen OP, Zhang N, Walberg F (1992) Metabolic compartmentation of glutamate and glutamine: morphological evidence obtained by quantitative immunocytochemistry in rat cerebellum. Neuroscience 46:519-534.

Palaiologos G, Hertz, I, Schoushoe A (1989) Role of aspartate aminotransferase and mitochondrial dicarboxylate transport for release of endogenously supplied neurotransmitter in glutamatergic neurons. Neurochem Res 14:359-366.

Pasteels B, Rogers J, Blachier F, Pochet R (1990) Calbindin and calretinin localization in the retina from different species. Vis Neurosci 5:1-16.

Pourcho R, Goebel DJ (1987) Visualization of endogenous glycine in the cat retina: an immunocytochemical study with Fab fragments. J Neurosci 7:1189-1197.

Pow DV (1993) Immunocytochemistry of amino acids in the rodent pituitary using extremely specific, very high titre antisera. J Neuroendocrinol 5:349-356.

Pow DV, Robinson SR (1994) Glutamate in some retinal neurons is derived solely from glia. Neuroscience 60:355-366.

Riepe RE, Norenburg MD (1977) Müller cell localisation of glutamine synthetase in rat retina. Nature 268:654-655.

Sakai H, Naka K-I (1986) Synaptic organization of the cone horizontal cells in the catfish retina. J Comp Neurol 245:107-115.

Schousboe A, Apreza CL, Pasantes-Morales H (1992) GABA and taurine serve as respectively a neurotransmitter and an osmolyte in cultured cerebral cortical neurons. In: Taurine (Lombardini JB et al., eds), pp 391-397. New York: Plenum.

Schwartz E (1982) Calcium independent release of GABA from isolated horizontal cells of the toad retina. J Physiol (Lond) 419:213224.

Schwartz E (1987) Depolarization without calcium can release $\gamma$-aminobutyric acid from a retinal neuron. Science 238:350-355.

Shank RP, Aprison MII (1979) Biochemical aspects of the neurotransmitter function of glutamate. In: Glutamic acid: advances in biochemistry and physiology (Filer LJ Jr et al., eds), pp 139-150. New York: Raven.

Shank RP, Campbell GLeM (1984a) $\alpha$-Ketoglutarate and malate uptake and metabolism by synaptosomes: further evidence for an astrocyte to neuron metabolic shuttle. J Neurochem 42:1153-1161.

Shank RP, Campbell GLeM (1984b) Glutamine glutamate and other possible regulators of $\alpha$-ketoglutarate and malate uptake. J Neurochem 42:1162-1169.

Sherry DM, Ulshafer RJ (1992) Neurotransmitter-specific identification and characterization of neurons in the all-cone retina of Anolis carolinensis. II. Glutamate and aspartate. Vis Neurosci 9:313-323.

Sherry DM, Yazulla S (1993) Goldfish bipolar cells and axon terminal patterns. J Comp Neurol 329:188-200.

Stell WK (1967) The structure and relationships of horizontal cells and 
photoreceptor-bipolar synaptic complexes in goldfish retina. Am J Anat 121:401-424.

Stell WK (1975) Horizontal cell axons and axon terminals in goldfish retina. J Comp Neurol 159:503-520.

Stell WK, Lightfoot DO (1975) Color-specific interconnections of cones and cone horizontal cells in the retina of the goldfish. J Comp Neurol 159:473-502.

Studholme KM, Yazulla S (1988) Localization of GABA and glycine in goldfish retina by electron microscopic postembedding immunocytochemistry: improved visualization of synaptic structures with LR white resin. J Neurocytol 17:859-870.

Swain PH, Davis SM (1978) Remote sensing: a quantitative approach. New York: McGraw-Hill.

Tabb JS, Ueda T (1991) Phylogenetic studies on the synaptic vesicle glutamate transport system. J Neurosci 11:1822-1828.

Tou JT, Gonzalez RC (1974) Pattern recognition principles. New York: Addison-Wesley.

Tufte ER (1983) The visual display of quantitative information. Cheshire, CT: Graphics Press.

Van Haesendonck E, Missotten L (1990) Glutamate-like immunoreactivity in the retina of a marine teleost, the dragonet. Neurosci Lett 111:281-286.

Van Haesendonck E, Missotten L (1991) Patterns of glutamate-like immunoreactive bipolar cell axons in the retina of the marine teleost, the dragonet. Vision Res 31:451-462.

Van Haesendonck E, Marc RE, Missotten L (1993) New aspects of dopaminergic interplexiform cell organization in the goldfish retina. J Comp Neurol 333:503-518.

Van Regenmortel MHV, Briand JP, Muller S, Plaué S (1988) Synthetic polypeptides as antigens. In: Laboratory techniques in biochemistry and molecular biology, Vol 19 (Burdon RH, van Knippenburg PH, eds), pp 1-215. New York: Elsevier.

Voaden MJ (1978) Localization and metabolism of neuroactive amino acids in the retina. In: Amino acids as chemical transmitters (Fonnum F, ed), pp 257-274. New York: Plenum.

Wagner H-J, Wagner E (1988) Amacrine cells in the retina of a teleost fish the roach (Rutilus rutilus): a Golgi study on differentiation and layering. Philos Trans R Soc Lond [Biol] 321:263-321.
Wässle H, Grünert U, Martin P, Boycott BB (1994) Immunocytochemical characterization and spatial distribution of midget bipolar cells in the macaque monkey retina. Vision Res 34:561-579.

Watt CB, Li H-B, Lam DMK (1985) The presence of three neuropeptides in putative glycinergic amacrine cells of an avian retina. J Comp Neurol 348:187-191.

Wolberg G (1990) Digital image warping. Los Alamitos, CA: IFEF Computer Society.

Wu J-Y (1976) Purification, characterization and kinetic studies of GAD and GABA-T from mouse brain. In: G $\Lambda \mathrm{B} \Lambda$ in nervous system function (Roberts E, Chase TN, Tower DB, eds), pp 7-56. New York: Raven.

Wülle I, Wagner H-J (1990) GABA and tyrosine lydroxylase inmmunocytochemistry reveal different patterns of colocalization in retinal neurons of various vertebrates. J Comp Neurol 296:173-178.

Yang X-L, Wu SM (1991) Feedforward lateral inhibition in retinal bipolar cells: input-output relation of the horizontal cell-depolarizing bipolar cell synapse. Proc Natl Acad Sci USA 88:3310-3313.

Yaqub A, Eldred WD (1991) Localization of aspartate-like immunoreactivity in the retina of the turtle ( $P_{\text {seudemys scripta). J Comp }}$ Neurol 312:584-598.

Yazulla S (1986) GABAergic mechanisms in retina. In: Progress in retinal research, Vol 5 (Osborne NN, Chader GJ, eds), pp 1-52. New York: Pergamon.

Yazulla S, Kleinschmidt J (1983) Carrier mediated release of GABA from retinal horizontal cells. Brain Res 263:63-75.

Yazulla S, Yang C-Y (1988) Colucalization of GABA and glycine immunoreactivities in a subset of retinal neurons in the tiger salamander. Neurosci Lett 95:37-41.

Zhang N, Walberg F, Laake J, Meldrum BS, Ottersen OP (1990) Aspartate-like and glutamate-like immunoreactivities in the inferior olive and climbing fibre system: a light microscopic and semiquantitative electron microscopic study in rat and baboon (Papio anubis). Neuroscience 38:61-80.

Zhang N, Laake I, Nagelhus F, Storm-Mathisen I, Ottersen OP (1991) Distribution of glutamine-like immunoreactivity in the cerebellum of rat and baboon (Papio anubis) with reference to the issue of metabolic compartmentation. Anat Embryol (Berl) 184:213 223. 